\title{
Achieving Fiscal Balance in Japan*
}

\author{
Selahattin İmrohoroğlu, Sagiri Kitao, and Tomoaki Yamada
}

February 14, 2013

\begin{abstract}
Japan is facing an aging population and already has the highest debt to GDP ratio among advanced economies. Further government spending is expected and there are legitimate concerns about the potential for Japanese debt to become a global issue.

In this paper we build a micro-data based, large-scale overlapping generations model for Japan in which individuals differ in age, gender, employment status, income, and asset holdings, and incorporate the Japanese pension rules in detail. We estimate age-consumption and age-earnings profiles from the Family Income and Expenditure Survey data, assume complete markets and use these to generate tax revenues and transfer payments for government accounts. We calibrate the model so that it produces the main macroeconomic indicators for 2010. Using existing pension law and fiscal parameters and the medium variants of fertility and survival probability projections, we produce predicted time paths for the ratio JGBs and the pension fund.
\end{abstract}

${ }^{*}$ Very preliminary and incomplete. We acknowledge the Statistics Bureau, the Ministry of Internal Affairs and Communications in Japan to use the Family Income and Expenditure Survey and the National Survey of Family Income and Expenditure for this project. Yamada gratefully acknowledge financial support from the Ministry of Education, Science, Sports, and Culture, Grant-in-Aid for Young Scientists (B) 24730173. 


\section{Introduction}

Japan has the highest debt to GDP ratio among advanced economies and faces a fast and large demographic transition to an older society. In addition, recent political developments suggest that the Japanese government may start a new round of government spending, renewing concerns over whether or not the Japanese sovereign debt may become a global problem. In the absence of a robust theory of government debt, it is difficult to evaluate statements regarding the massive quantity Japanese government bonds (JGBs), their prices, and, if and when bond market participants will stop buying them. One can, however, develop a model to measure what will happen to JGBs and the underlying reasons and that is what we do in this paper.

In particular, we build a micro-data based, large-scale overlapping generations model for Japan in which individuals differ in age, gender, employment status, income, and asset holdings, and incorporate the Japanese pension rules in detail. We estimate age-consumption and age-earnings profiles from the Family Income and Expenditure Survey data, assume complete markets and use these to generate tax revenues and transfer payments for government accounts. We calibrate the model so that it produces the main macroeconomic indicators for 2010. Using existing pension law and fiscal parameters and the medium variants of fertility and survival probability projections, we produce predicted time paths for the ratio JGBs and the pension fund. In addition, we decompose annual net borrowing requirements that integrate to the JGBs into non-pension primary deficit, pension deficit, and net interest payments on JGBs net of the pension fund.

Our analysis highlights 4 key quantitative findings:

- Pension and non-pension deficits contribute about the same, just about 4 percentage points each, to new borrowing requirements over the next few years, with net interest on debt playing a much smaller role, thanks to the low real interest rate on JGBs in the current economic environment.

- With the consumption tax rate expected to rise from $5 \%$ to $10 \%$ in 
2014-2015, there is a significant improvement in the non-pension deficit and then a gradual rise over time as non-pension transfers and health expenditures start to rise.

- There is an initial, significant decline, and later, a smooth decline in the pension deficit. However, in about 25 years the pension deficit starts to rise again, eventually stabilizing at about $3.5 \%$ annually.

- Net interest payments on JGBs eventually dominate net borrowing requirements despite the low $1 \%$ interest rate; the stock of debt is just too large.

These findings suggest that no single policy can have a major impact on fiscal sustainability. Two key suggestions that emerge from our analysis are 1) further pension reform, and, 2) policies that raise female labor force participation.

\section{Overview of the Literature}

Our paper contributes to a growing literature that relies on workhorse macro models to shed light on the severity of fiscal adjustment Japan needs to make, the policy options that are available, and the economic consequences of these alternative policy actions.

The backdrop for this effort can be described as follows. The Japanese economy has essentially been stagnant since 1990. The policy rate has been lowered to essentially zero for more than a decade. Several rounds of fiscal stimulus packages since early 1990s have resulted in the highest debt to GDP ratio in the developed world. Japan's net debt to GDP is about $120 \%$ and its gross debt to GDP is above $200 \%$ by the end of 2010 .

In addition, Japan has the fastest aging population among the developed economies. Therefore, Japan serves as a laboratory for i) how severe demographic and fiscal challenges are, ii) how various government policies may 
affect fiscal sustainability, and, iii) how these policies affect the individuals' welfare given the projected demographics and fiscal paths.

The expected aging of the population will raise pension payments as more and more retirees will receive old age pensions, raising the transfers to output ratio. At the same time, health expenditures will also rise as the fraction of elderly in the society increases, pushing up the government purchases to output ratio.

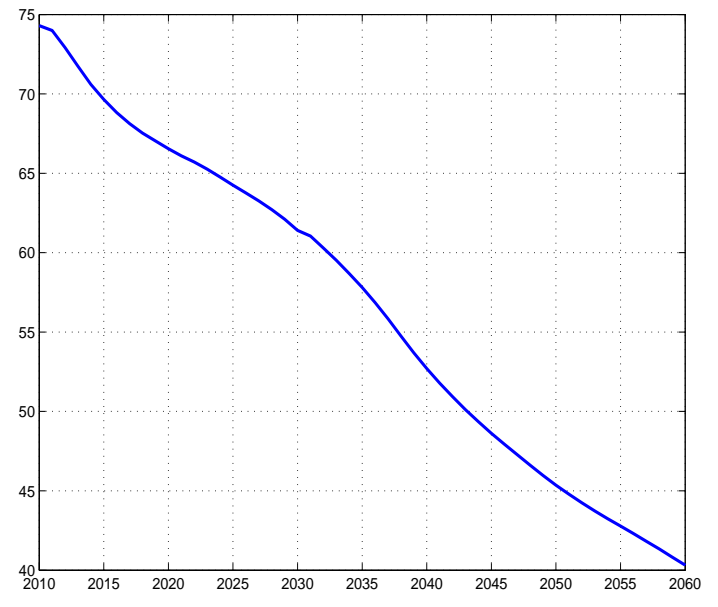

(a) Working age population

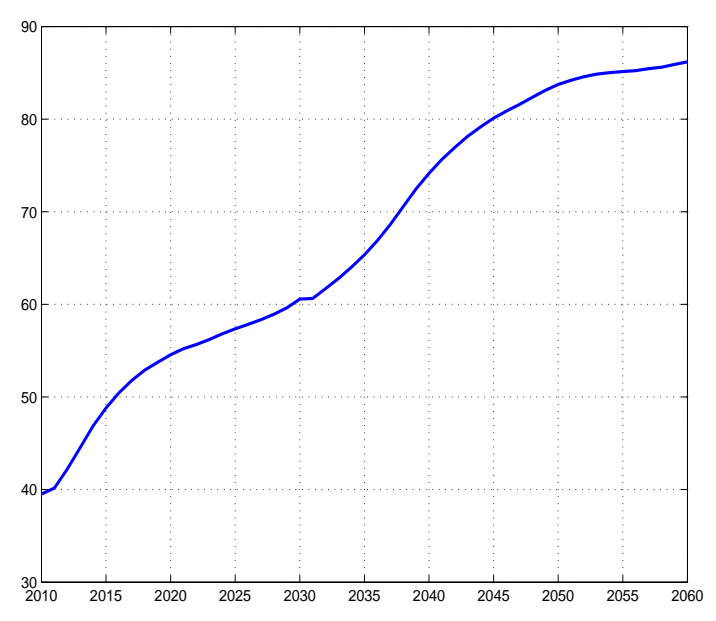

(b) Old-age dependency ratio

Figure 1: Projected demographics: 2010-2060

Figure 1 shows the projected population in Japan between the working ages of 20 and 64 and the old-age dependency ratio defined as the ratio between the population above age 65 and 20-64. ${ }^{1}$ With the increase in the fraction of 65 and older, the working age individuals will have to increasingly support the elderly through some combination of higher taxes, lower leisure, lower consumption, or lower future benefits for themselves, if current projections of future benefits to current cohorts are to be maintained.

\footnotetext{
${ }^{1}$ Projections are based on the estimates of the survival rates and fertility rates by the National Institute of Population and Social Security Research. http://www.ipss.go.jp/index-e.asp
} 
Using a neoclassical growth model, İmrohoroğlu and Sudo (2010) examine the impact of a rise in the consumption tax rate from $5 \%$ to $15 \%$ on the primary deficit to GDP ratio. Despite a temporary improvement in the primary balance, their quantitative results indicate that a much larger fiscal adjustment is needed to achieve fiscal sustainability. İmrohoroğlu and Sudo (2011) explore whether faster productivity growth can increase the tax base sufficiently to reduce debt to GDP to manageable levels. They find that only a growth miracle, such as a $6 \%$ real growth rate over 10 years, could achieve a fiscal adjustment of the size that Japan is facing.

Braun and Joines (2011) build an overlapping generations model that incorporates the demographic transition and calculate economic projections for Japan. Their findings suggest that in the absence of any reform, the consumption tax rate will have to rise to about $37 \%$ in order to achieve fiscal sustainability.

Hoshi and Kashyap (2012) use a narrative to argue that zombie financing and very large spending programs have significantly contributed to the already large projected fiscal burden of the demographic transition. In addition to suggesting fiscal consolidation and major regulatory and microeconomic reforms, they also recommend opening up the Japanese economy. In particular, they suggest a stronger push to become a member of the Trans Pacific Partnership (TPP) and to take immigration seriously.

Hoshi and Ito (2012) use back-of-the-envelope calculations for sustainability. Emphasizing the seemingly unending appetite of Japanese private sector for JGBs in the face of extremely high prices for such bonds, they argue that there is an upper bound on the private sector's ability to finance further new borrowing by the government. They predict that under certain assumptions this threshold will be reached in about 2022 and the yields on JGBs will rise, even before 2022. This would then be followed by Greece-like events of fiscal austerity, financial instability and even inflation.

Hansen and İmrohoroğlu (2011) use a standard growth model, amended to include debt, to measure the size of the fiscal burden in the form of additional 
taxes required to meet these obligations that maintain current promised levels of per capita public pension and health services. The fiscal adjustment needed is about a 30 percentage point increase in taxes, using either the consumption tax rate or the labor income tax rate. They find that the latter is far more distorting than the former, leading to a significant loss in welfare, highlighting the need to contain public spending and explore policies to enlarge the tax base.

In this paper, we use a very rich, detailed overlapping generations structure to evaluate the severity of the demographic and fiscal challenges Japan is facing. We calculate projections of future government budget balances and debt, and conduct counterfactual 'accounting' exercises to assess the impact of possible fiscal responses to future shocks and how these policies change the fiscal sustainability in Japan.

We do not model individual decisions on saving/consumption and labor supply. As such, our model is not suitable to conduct a welfare analysis to study the effects of reforms or the demographic change. We do, however, incorporate significant details of the pension system in Japan, including the distinction of three different types of pension programs, eligibility, non-linear functions of benefits and contributions/premium in each program. In addition, we capture the unique and important heterogeneity among the labor force, male versus female, regular vs irregular employment, which have very important implications for the funding of the pension program. All of these important details are essential in understanding the current evaluation of the Japanese pension program, as well as its future projection.

It is, however, impossible to incorporate all of these in a model in which individuals are optimizing due to computational complexity. A natural first step is to develop a rich, detailed measurement device to see which events or policies are 'big' and then as a second and critical step go to an optimizing model with a manageable state space to conduct welfare analysis. In future research, we plan on developing this behavioral model and evaluate policy options. 


\section{Model}

In this section, we start with a description of the government accounts that will allow us to compute implications of policies and shocks on the future path of Japanese government macroeconomic outcomes. Later in the section we will describe the economic environment and individual variables, and how we aggregate them to derive main macroeconomic indicators.

\subsection{Government and fiscal policies}

The government raises revenues through taxation and issuance of one-period real debt to finance public consumption transfers to individuals as well as debt repayment and interest payments on outstanding debt. The government also runs the public pension scheme and provides pension benefits to retirees.

Government budget: In each period the government finances its expenditures $G_{t}$, transfers to individuals $T R_{t}$, pension benefits to retirees $P_{t}$ and the cost of debt servicing through taxation $T_{t}$, issuance of new debt $B_{t+1}$, and collection of pension premium $P R_{t}$. At the beginning of period $t$, besides the the government debt $B_{t}$, it holds assets in the pension fund denoted as $F_{t}$, which can be used to pay for the pension benefits. Therefore the net debt of the government is $B_{t}-F_{t}$. The government budget constraint is given as follows.

$$
B_{t+1}-F_{t+1}=\left(1+r_{b, t}\right) B_{t}-\left(1+r_{f, t}\right) F_{t}+G_{t}+T R_{t}+P_{t}-T_{t}-P R_{t} .
$$

Here $\left(1+r_{b, t}\right) B_{t}$ is the principal and interest payments on the stock of government debt. We assume that the government issues one-period, real bonds at interest rate $r_{b, t}$, and we abstract from money creation and the inflation. $r_{f, t}$ denotes the return on the pension fund.

Our objective is to calculate a time path for $B_{t+1}$ between 2011 and 2100 under various assumptions on the economic environment, fiscal and monetary policies, demographics and labor and family structures. As such, we must 
pay careful attention to how we compute the right hand side of equation (1). In other words, we would like to tie these to data and behavior as much as possible. We describe below how the aggregates in (1) are composed of individual variables. As we describe details in the following sections, $n_{i, j, e, t}$ denotes the number of individuals in the state vector of $\{i, j, e\}$ at time $t$, which represents age $i$, gender $j$ and employment type $e$.

$$
\begin{aligned}
T_{t} & =\tau_{c, t} \sum_{i, j, e} c_{i, t} n_{i, j, e, t}+\tau_{a, t} r_{a, t} \sum_{i, j, e} a_{i, t} n_{i, j, e, t}+\tau_{l, t} \sum_{i, j, e} y_{i, j, e, t} n_{i, j, e, t}+\tau_{l s, t} \sum_{i, j, e} n_{i, j, e, t} \\
T R_{t} & =\sum_{i, j, e} t r_{i, j, e, t} n_{i, j, e, t} \\
G_{t} & =\sum_{i, j, e} g_{i, j, e, t} n_{i, j, e, t} \\
P_{t} & =\sum_{i, j, e} p_{i, j, e, t} n_{i, j, e, t} \\
P R_{t} & =\sum_{i, j, e} \tau_{p, t}\left(y_{i, j, e, t}\right) n_{i, j, e, t}
\end{aligned}
$$

$T_{t}$ represents taxes on four sources of revenues; consumption at proportional rate $\tau_{c, t}$, capital income at rate $\tau_{a, t}$, labor income at rate $\tau_{l, t}$ and a lump-sum tax of $\tau_{l s, t}$. $t r_{i, j, e, t}$ represents non-pension transfer payments given to individuals. $g_{i, j, e, t}$ denotes the per-capita government purchases for individuals in state $\{i, j, e\}$ at time $t . p_{i, j, e, t}$ represents the pension benefit to each retiree. $\tau_{p, t}(y)$ is the contribution to the public pension system by each working-age insured individual, which depends on earnings $y$.

Pension benefit: Pension benefits in Japan follow a three-tiered structure; the basic pension (Kokumin Nenkin), the employees' pension insurance (Kosei Nenkin Hoken) and an optional scheme and the government runs the first two schemes jointly. ${ }^{2}$ Individuals between the ages of 20 and 60 are eligible and required to participate in the basic pension and the benefit is a fixed

\footnotetext{
${ }^{2}$ The third optional retirement plan is a semi-private plan, which is closer to a private saving plan and we will not explicitly model it.
} 
amount if an individual has been insured throughout the period of eligibility. The benefits from the employees' pension insurance are based on career earnings of an individual. To approximate the system, we assume that the pension benefits $p_{i, j, e, t}$ consist of two parts, a lump-sum component, which represents the basic pension and a part that is proportional to average earnings of an individual, which approximates the employees' pension insurance. More details are provided in section 4.3 .

The payment of the public pension benefits is financed by the combination of the premium paid by the insured, contribution from the general government budget and the pension fund. The law of motion for the pension fund is given as follows.

$$
F_{t+1}=\left(1+r_{f, t}\right) F_{t}+P R_{t}+X_{t}-P_{t}
$$

Here $X_{t}$ denotes the contribution from the general government budget to the payment of pension benefits.

The above computations rely on estimates of income by an age $i$ individual of gender $j$, with a type $e$ employment at time $t$ and how this object is related to the consumption and asset holding decision of the same individual. Once we specify these objects, then our aggregation rules above will yield the model's implications on the future path of government assets $B_{t+1}$.

\subsection{Demographics}

Our model is populated by individuals that differ in age, gender and employment status. We denote the state vector of an individual at time $t$ as $\{i, j, e\}$. $i$ represents the age of an adult individual, $j \in\{m, f\}$ the gender (male or female) and $e$ the employment status as discussed on section 3.3.

The age of an individual including dependent children is denoted as $\widetilde{i}$, differently from the adult age $i . \widetilde{n}_{\tilde{i}, j, e, t}$ represents the number of individuals of type $\{\widetilde{i}, j, e\}$ at time $t$.

Individuals can live up to $\widetilde{I}$ years. Life-time is uncertain and agents of age $\widetilde{i}$ and gender $j$ at time $t$ face a conditional probability of $s_{i, j, t}$ to survive from 
age $\tilde{i}$ at time $t$ to age $\widetilde{i}+1$ at time $t+1$. The fertility rate (the number of children per woman in a year) of an age $\widetilde{i}$ female at time $t$ is given as $\phi_{\tilde{i}, t}$.

Individuals enter the economy at age $I_{A}$ (become adult) and begin economic activities, participating in the labor market and making consumption and saving decisions.

We denote by $\widetilde{n}_{\tilde{i}, j, t}$ the number of individuals of age $\widetilde{i}$ and gender $j$ at time $t$ and by $\widetilde{\mathbf{n}}_{t}$ the $2 \widetilde{I} \times 1$ vector of age groups by gender.

The law of motion of the population between time $t$ and $t+1$ is given by $\widetilde{\mathbf{n}}_{t+1}=\Gamma_{t} \widetilde{\mathbf{n}}_{t}$, where $\Gamma_{t}$ is a time varying matrix of size $2 \widetilde{I} \times 2 \widetilde{I}$ composed by fertility rates and survival probabilities of individuals of both genders.

$$
\begin{aligned}
& \widetilde{\mathbf{n}}_{t}^{\prime}=\left[\widetilde{n}_{1, m, t}, \widetilde{n}_{2, m, t}, \cdots, \widetilde{n}_{\widetilde{I}, m, t}, \widetilde{n}_{1, f, t}, \widetilde{n}_{2, f, t}, \cdots, \widetilde{n}_{\widetilde{I}, f, t}\right]
\end{aligned}
$$

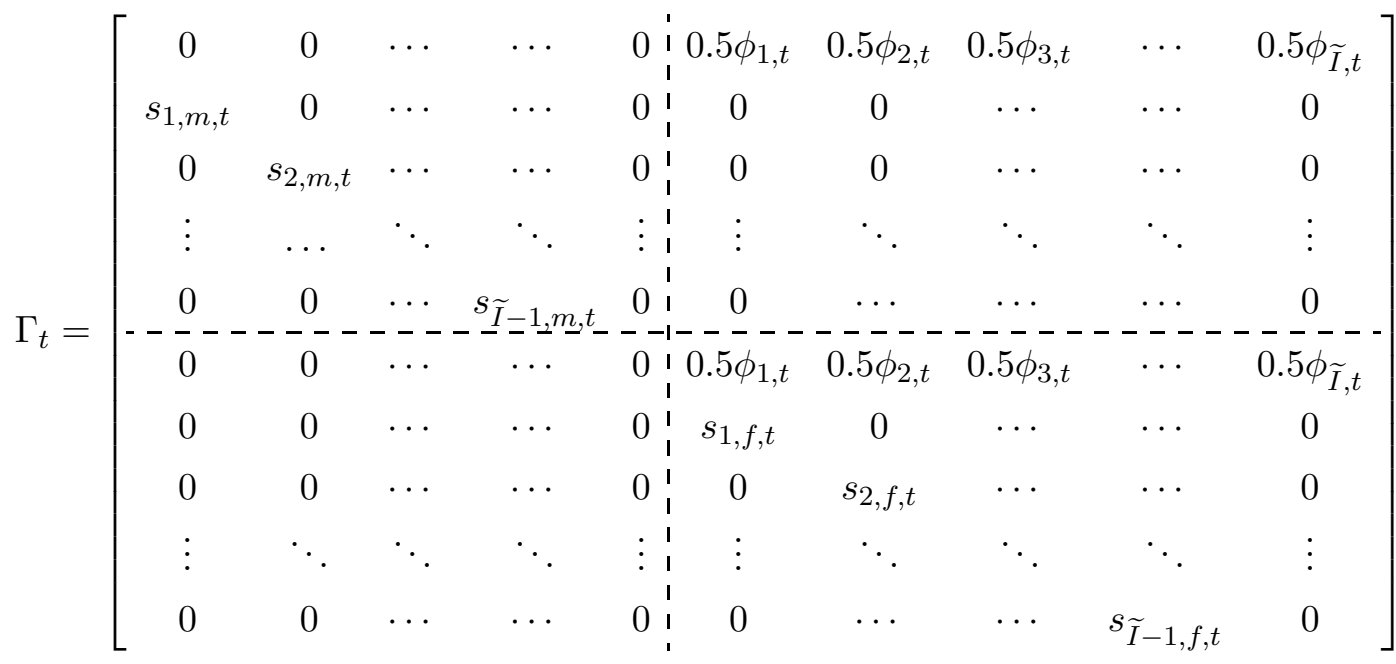

$$
\begin{aligned}
& \widetilde{\mathbf{n}}_{t+1}=\Gamma_{t} \widetilde{\mathbf{n}}_{t}
\end{aligned}
$$

In what follows, we define the adult age $i$, which starts at age $I_{A}$. The age of an individual $\widetilde{i} \geq I_{A}$ is $i=\widetilde{i}-I_{A}+1$. 


\subsection{Labor force participation and earnings}

In each period an individual is either employed at a regular job $(R)$, a contingent job $(C)$, self-employed $(S)$ or not working $(U)$. The employment status is denoted as a state $e \in\{R, C, S, U\} .{ }^{3}$ Earnings of type $\{i, j, e\}$ individuals at time $t$ is $y_{i, j, e, t}$. Note that $y_{i, j, e, t}=0$ for individuals that are not working.

\subsection{Consumption and asset profiles}

In order to derive revenues from consumption and capital income taxes, it is necessary to impute the path of consumption and wealth for each individual over time.

We assume that age-profile of individual consumption relative to the lifetime wealth defined as discounted sum of disposable income is time-invariant. We allow, however, the number of dependent children to affect the consumption allocations. The factor of adjustment by an additional dependent child will be time-invariant (possibly dependent on the age of children), but the total adjustment will vary as the fertility rates and the number of dependent children at each age evolve over time. We assume that the consumption of both male and female individuals of the same age will be adjusted by the same fraction to account for the consumption of dependent children.

Individuals are assumed to be dependent children for $I_{A}-1$ periods. Each dependent is supported by a pair of male and female (parents) of the same age for their consumption. The consumption of an individual is adjusted according to the number (and possibly ages) of dependent children. Let $\tilde{d}_{t, \tilde{i}, k}$

\footnotetext{
${ }^{3}$ The first represents a full-fledge employment (seishain) and the second is an employment at a non-regular, temporary or dispatch job (hi-seishain or hi-seiki-koyou). Note that the latter is different from a part-time job in the U.S. It does not necessarily mean the individuals at a contingent job works less than full-time equivalent hours. It is an employment under a different type of contract than in a regular job, where employment is guaranteed only a fixed period and often the salary is significantly lower, as discussed in section 4 . The last employment status includes both unemployment and not-in-labor-force.
} 
denote the number of dependents of age $k$ that parents of age $\widetilde{i}$ support at time $t$, which coincides with $\phi_{\tilde{i}-k+1, t-k+1} \cdot{ }^{4}$ The total number of children for a mother of age $\widetilde{i}$ at time $t$ is given as $d_{t, \tilde{i}}=\sum_{k=1}^{I_{A}-1} \tilde{d}_{t, \tilde{i}, k} o_{k}$ (possibly adjusted by the age-dependent weight $o_{k}$ ).

We estimate the age-specific fraction of the discounted present value of income $\tilde{\lambda}_{i}$ consumed at each age $i$ from the consumption data for individuals. The equivalence adjustment factor $\lambda_{i, t}$ takes into account the adjustment in consumption allocation for children implied by the path of fertility rates. $\lambda_{i, t}=\tilde{\lambda}_{i}\left(1+d_{t, \tilde{i}} \nu\right)$ where $\nu$ represents adult consumption equivalence for dependent children.

Individuals are assumed to own no wealth as they enter the economy and start economic activities. We assume that there are annuity markets to cover the event of early death and each individual is entitled to keep the share of the assets of the deceased in the same cohort and gender. For simplicity, we also assume that the consumption profile is determined based on the expected life-time income. ${ }^{5}$

Consumption of gender $j$ individuals that belong to cohort $t+1$ (that is individual "born" at the first adult age $i=1$ at time $t+1$ ) is given as follows.

$$
\begin{aligned}
& c_{i, j, t+i}\left(1+\tau_{c, t+i}\right)=\widetilde{\lambda}_{i, t} \sum_{m=i_{A}}^{I} \frac{1}{\prod_{k=1}^{m}\left[1+r_{a, t+k}\left(1-\tau_{a, t+k}\right)\right]} S_{m, j, t+m} \\
& \sum_{e} \frac{n_{m, j, e, t+m}}{\sum_{e} n_{m, j, e, t+m}}\left[\left(1-\tau_{l, t+m}\right) y_{m, j, e, t+m}-\tau_{p, t}\left(y_{m, j, e, t+m}\right)-\tau_{l s, t}+p_{m, j, t+m}+t r_{m, j, e, t+\left(\boldsymbol{m}_{m}\right)}\right)
\end{aligned}
$$

where $\widetilde{\lambda}_{i, t}=\lambda_{i, t} S_{i, j, t+i} / \prod_{k=1}^{i}\left[1+r_{a, t+k}\left(1-\tau_{a, t+k}\right)\right] . S_{i, j, t+i} \equiv \prod_{k=1}^{i} s_{k, j, t+k}$ is the unconditional survival probability of gender- $j$ agent born at time $t$ until age $i$ at time $t+i$. The summation on the right hand side of the equation represents the expected life-time net income discounted by the sequence of

\footnotetext{
${ }^{4}$ In this computation, we abstract from the death of children given the very low mortality rates of an infant and children.

${ }^{5}$ Implicit in the assumptions is that individuals have an access to technology to insure against both mortality and employment risks within cohort and gender.
} 
the interest rates and survival probabilities to reflect the access to the annuity markets. The age-specific profile of assets can be computed recursively given the life-cycle profile of income net of taxes and transfers and the path of consumption. They will be used to compute the tax base for capital income taxation.

$$
\begin{aligned}
& c_{i, j, t+i}\left(1+\tau_{c, t+i}\right)+s_{i, j, t+i} a_{i+1, t+i+1}=\left(1-\tau_{l, t+i}\right) y_{i, j, e, t+i} \\
& -\tau_{p, t}\left(y_{i, j, e, t+i}\right)-\tau_{l s, t}+p_{i, j, t+i}+t r_{i, j, e, t+i}+\left[1+r_{a, t+i}\left(1-\tau_{a, t+i}\right)\right] a_{i, t+(t)}(4)
\end{aligned}
$$

\section{Parametrization of the model}

We calibrate parameters of the model to match Japanese economy in 2010, which is the initial year to start simulation. The model period is one year. Table 1 summarizes the parametrization of the model.

\subsection{Demographics}

Individuals enter the economy at the age of 20 , and live to a maximum age of 110 , i.e., $I_{A}=21$ and $\tilde{I}=111$. Conditional survival probabilities $s_{i, j, t}$ and fertility rates $\phi_{i, t}$ are based on the estimates and projections of the National Institute of Population and Social Security Research (IPSS) released in 2012. ${ }^{6}$ The IPSS provides the population projection for Japan between 2011 and 2060. As we focus on the transition dynamics from 2010 to 2100 , we use the conditional survival probabilities and fertility rate in 2060 to extend the projection from 2060 to 2100 . The projections of fertility rates and survival probabilities consist of three variants of estimates; a low variant, a medium variant and a high variant of each. We use the medium variants of both the fertility and survival probability rates as a benchmark and examine other

\footnotetext{
${ }^{6}$ The population projection is available from http://www.ipss.go.jp/site-ad/index english/esuikei/gh2401e.asp.
} 
projections in section 6 . Figure 2 shows the three variants of the total fertility rate (TFR). ${ }^{7}$ In 2010 , the TFR is 1.39 , which accelerates declining population. Figure 3 plots the life expectancy by gender.

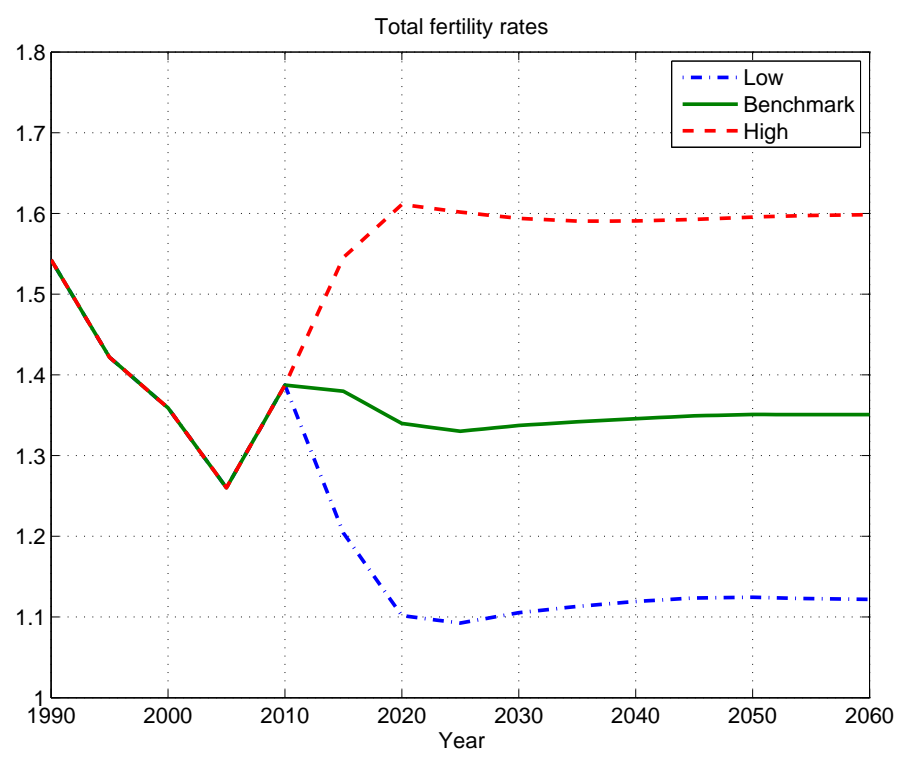

Figure 2: Total Fertility Rate

\footnotetext{
${ }^{7}$ The population projection by the IPSS provides future fertility rates of women between 15 and 49 .
} 


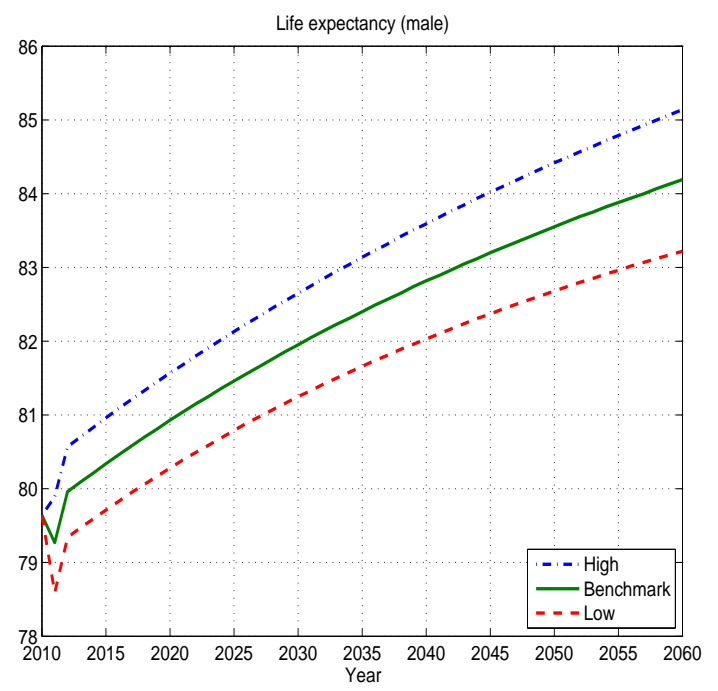

(a) Male

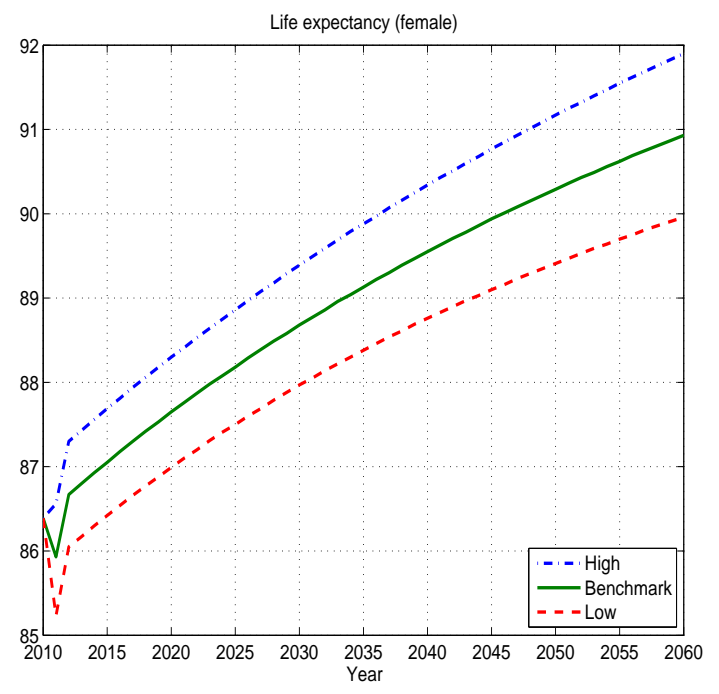

(b) Female

Figure 3: Life Expentancy

For the population distribution in 2010, we use the distribution by age and gender from Population Census by the Ministry of Internal Affairs and Communications. We compute population and labor market dynamics from the initial population distribution, the TFR, and the conditional survival probability rates. The number of dependents $\left\{\tilde{d}_{t, \tilde{i}, k}\right\}$ is also calculated from the projected population distribution

\subsection{Labor market and earnings}

We compute the labor force participation rate of regular $(\mathrm{R})$, contingent job workers (C) and self-employed (S) for male and female from the Labor Force Survey in 2010 by the Ministry of Internal Affairs and Communications. ${ }^{8}$ Notworking $(\mathrm{U})$ is defined as the residual of the labor force participation rates of

\footnotetext{
${ }^{8}$ We use the following categories for regular job worker, contingent job workers and self-employed workers respectively: Regular job workers consist of "regular employee" and "executive of company or corporation". Contingent job workers are defined as a worker who engaged in "part-time
} 
the three categories. Note that the non-working includes unemployed, discouraged workers, and housewife. Figures 4 shows the labor force participation rate by the job types and gender. Labor force participation rates of male workers are high for their working age. In contrast, those of female workers are low compared with other developed countries and it appears M-shaped due to child-bearing in their middle age. We assume that the employment status distribution is invariant over time.

As will be described later, public pension contribution and benefit depend on the employment status. For example, self-employed workers participate in the basic pension and the benefit is a fixed amount. On the other hand, regular job workers contribute not only the basic pension but the employees' pension insurance. The category distribution is generated from the labor force participation rates.

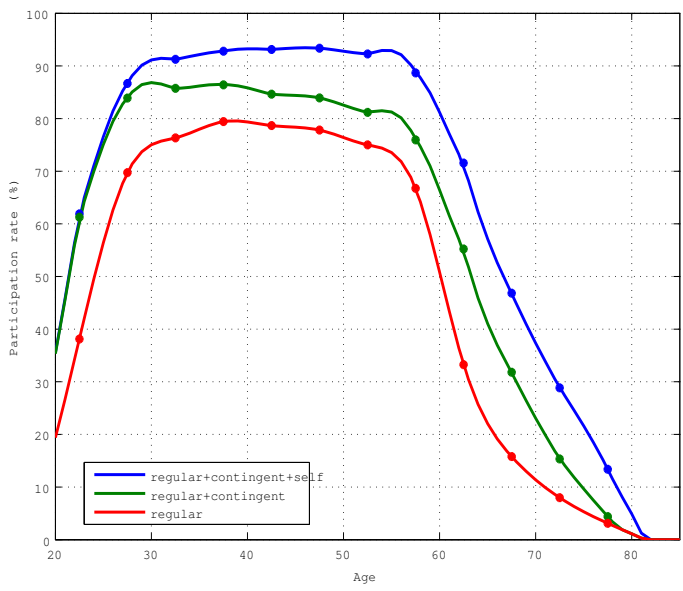

(a) Male

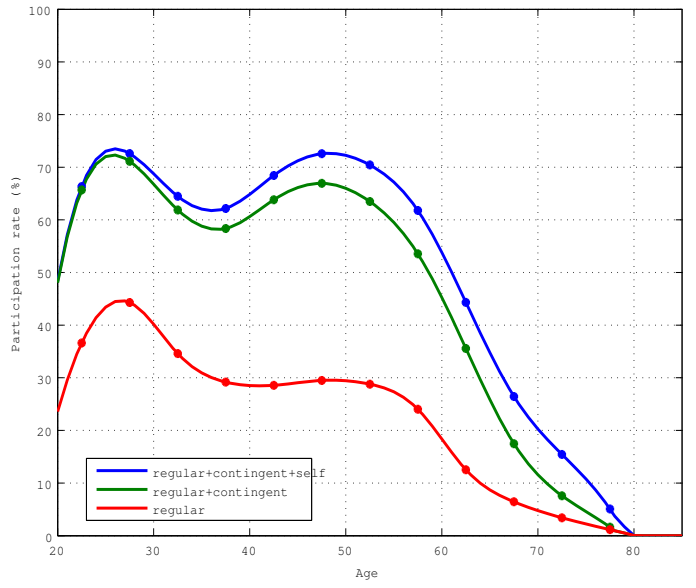

(b) Female

Figure 4: Labor force participation rate

worker, Arbeit", "dispatched worker from temporary labor agency", "contact employee or entrusted employee" or "other". Self-employed are "self-employed worker with/without employee", "doing piecework at home", or "family worker". Not-working is the sum of "unemployed person" and "not in labor force". 
Earnings profiles of regular workers and contingent job workers are computed from the Basic Survey on Wage Structure (BSWS) in 2010, which is conducted by the Ministry of Health, Labour, and Welfare. The BSWS collects data from private establishments, which implies that it targets regular/irregular employees, and self-employed workers are excluded. We use the National Survey of Family Income and Expenditure (NSFIE) in 2004 to compute the earnings profile of self-employed workers. ${ }^{9}$ The NSFIE collects annual income of both household head and spouse. As we can identify sex, age and occupation of household head and spouse, we calculate income profiles of self-employed workers by gender. ${ }^{10}$ We assume that the shape of the earnnings profiles is invariant over time although TFP growth shifts up the profiles. As we consider three types of workers by gender, we calibrate six types of earnings profiles (Figure 5).

\footnotetext{
${ }^{9}$ Although the NSFIE does not directly target self-employed workers, Genda and Kambayashi (2002) investigate income of self-employed workers using the NSFIE. For details on the NSFIE, see Lise et al. (2013).

${ }^{10}$ We use the following categories of occupation as self-employed worker: "merchants and artisans", "private administrators", "households with income from agriculture, forestry and fishery", "professional services". Annual income is the sum of "wage and salaries", "income from agriculture, forestry and fishery", "income from business other than agriculture, forestry and fishery", and "homework".
} 


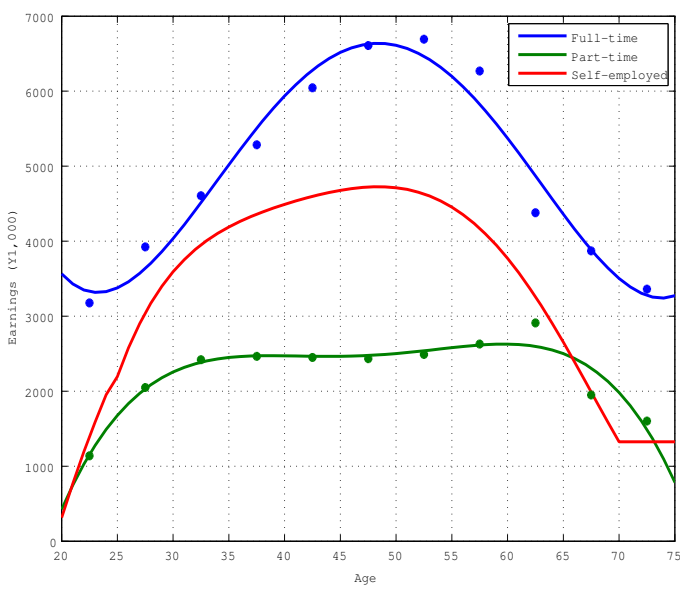

(a) Male

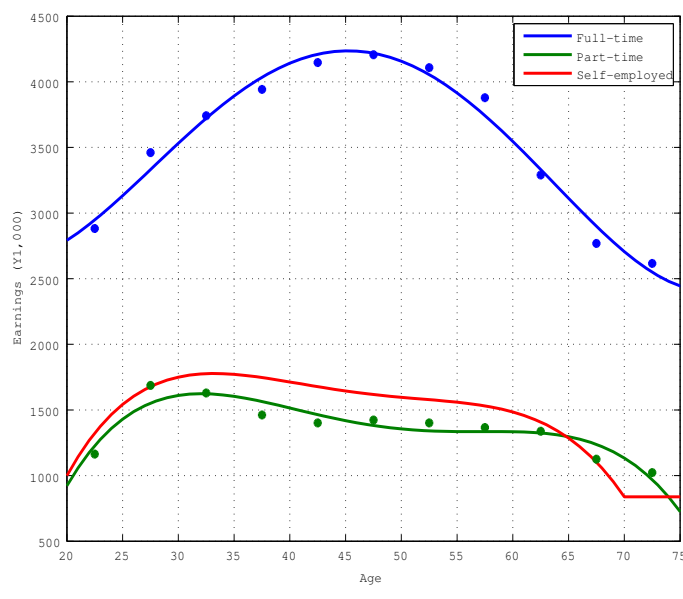

(b) Female

Figure 5: Approximated earnings profiles by job types

\subsection{Government}

Public pension: As discussed in section 3.1, the two main pillars of the public pension schemes in Japan are the basic pension (Kokumin Nenkin) and the employees' pension insurance (Kosei Nenkin Hoken). ${ }^{11}$ We assume that all individuals between age 20 and 60 participate and contribute to the basic pension. The annual benefit of the basic pension is $¥ 792,100$ in 2010 for an individual who has contributed for the entire 40 years and it is reduced proportionally according to the number of months that the individual was not covered. The second pillar of the Japanese pension system is the compulsory employees pension insurance which depends on earnings. Only category 2 insured persons can recieve the earnings-related part of the public pension.

\footnotetext{
${ }^{11}$ There are three types of pension subscribers. Category 1 subscribers of the pension scheme are students, farmers, self-employed, and others not in categories 2 and 3. Category 2 participants are workers in establishments with more than 5 workers and category 3 consists of non-working spouses of category 2 workers. Premium payment of category 2 participants will contribute to the earnings-related employees' pension insurance.
} 
In the model, individuals start receiving the pension at the full retirement age $i_{R, b}$ for the basic pension and $i_{R, e}$ for the employees' pension insurance. ${ }^{12}$ The retirement age has differed by gender and by the insurance programs. For cohorts born before 1934, the retirement age of the employees' insurance program was 60 for males and 56 for females and the basic pension's retirement age was 60 for both male and female, but all the retirement ages are set to rise gradually and they will all reach 65 for cohorts born after 1965 . We will incorporate the transitional retirement ages by the program and gender in the model.

We approximate the Japanese pension system using a formula given below.

$$
p_{i, j, t}=x_{t}\left[p_{i, j, t}^{b}+\xi_{i, t} \times \bar{y}_{i, j, t}\right]
$$

where $p_{i, j, t}^{b}$ is the basic pension mentioned above for retirees of age $i$ and gender $j$ at time $t, \xi_{t}$ affects the replacement rate, and $\bar{y}_{i, t}$ denotes their average past earnings. Note that the pension benefit depends on job types.

Faced with demographic aging, Japanese government has introduced an automatic adjustment scheme after 2004, which is called the "macroeconomic slide", to attain the budget balance for public pension system. The main idea is such that the growth rate of public pension benefit keeps less than the sum of the real wage growth rate and inflation rate.

$x_{t}$ is the slide factor that represents the adjustment through the macroeconomic slide. To keep the replacement rate constant, one needs to shift the public pension benefit parallel with the sum of wage growth rate and the inflation rate. In contrast, the macroeconomic slide factor is determined as follows. Denote the inflation rate as $\pi_{t}$, growth rate of real wage as $g_{t}^{w}$, "slide adjustment rate" (defined below) as $s_{t}$. For new recipients (Shinki-saitei),

\footnotetext{
${ }^{12}$ It is possible to apply for early payment of pension benefits starting at age 60 or delayed payment after the pensionable age. The benefits are adjusted to reflect the penalty and credit associated early and delayed withdrawal of benefits, respectively. The assumption of a common retirement age is mainly for simplicity but the majority of individuals start to collect benefits at the full retirement age of 65 (MHLW, 2011).
} 
define $x_{t}^{*}=g_{t}^{w}+\pi_{t}$ and the slide factor $x_{t}$ is given as

$$
\begin{aligned}
& x_{t}=\max \left\{x^{*}-s_{t}, 0\right\} \text { if } x^{*} \geq 0 \\
& x_{t}=x^{*} \text { if } x^{*}<0
\end{aligned}
$$

For existing recipients $\left(K i\right.$-saitei), define $x_{t}^{*}=\pi_{t}$ and the slide factor $x_{t}$ is determined as in the above formula. Therefore, if the sum of growth rate of wage and inflation rate is strictly larger than the slide adjustment rate, the actual replacement rate gradually delines as time goes by.

The slide adjustment rate $s_{t}$ consists of two parts. One that reflects the change in the number of insured and the second that is associated with a rise in life-expectancy (or expected duration of pension). The slide adjustment rate is approximately estimated at $0.9 \%$ ( $0.6 \%$ and $0.3 \%$ for each factor) on average. In the official projection of the pension fund, they assume the slide adjustment occurs from 2012 to 2038.

In the benchmark case, we assume inflation rate of $1 \%$ to work the macroeconomic slide although it may appears to be slightly higher than the realized inflation rates in recent years. ${ }^{13}$

Contribution to the pension system $\tau_{p, t}\left(y_{i, j, e, t}\right)$ depends on the three types of categories. Category 1 insured person pays a fixed amount to the basic pension system. The monthly premium for the basic pension will rise from the current $¥ 14,940$ by $¥ 280$ every year to $¥ 16,900$ in 2017 . Thereafter, the premium stays at $¥ 16,900$. Category 2 insured person, who are typically saralied workers, contribute a constant fraction of labor earnings. The tax rate on earnings for the employer pension is set to rise from the current $16.058 \%$ in 2010 by $0.354 \%$ every year to $18.3 \%$ in 2017 . Thereafter, the rate stays at $18.3 \%$. Category 3 insured person, who are spouse of category 2, contribute nothing, because the premium is interpreted to be paid by her/his spouse.

All the three categories are closely related with their job types. For example, a large part of category 1 insured person is self-employed, and main part

\footnotetext{
${ }^{13}$ In fact, the macroeconomic slide does not work after introducing the scheme in 2004 due to deflation.
} 
of contingent workers are also categorized here. Most of the regular employees are categorized into category 2 insured person. We calibrate the category distribution consistent with the job type distribution.

Public Pension Fund and Japanese Government Debt: The pension fund $F_{t}$ follows the dynamics as described in equation (2). The initial asset $F_{1}$ is set at 178.3 trillion yen, the level of total assets in all public pension programs excluding employees' pension funds (Kosei Nenkin Kikin) at the end of FY2009. ${ }^{14}$ We assume that the return on the pension fund $r_{f, t}$ is $2.0 \%$, which is close to the average real return of the fund in the past decade. ${ }^{15}$

The government debt $B_{t}$ evolves according to the formula (1). Initial debt $B_{1}$ is set at 678.6 trillion yen, or about $140 \%$ of the GDP, which corresponds to the total liabilities of central and local government net of financial asset at the end of 2009. More concretely, from the SNA table "Closing Stocks of Assets/Liabilities classified by the Sub-sectors of General Government", liabilities of central and local governments in 2009 were 786 trillion yen and 184 trillion yen respectively. We subtract financial asset of central government (200 trillion yen) and local government (72 trillion yen) from the sum of liabilities to calculate the net government debt. Note that it does not include the assets held in the social security funds, which we keep track of separately. We assume that the interest rate paid on the government debt $r_{b, t}$ is $1 \%$.

Taxes: Consumption tax rate $\tau_{c, t}$ in 2010 is set at 5\%. As the government already schedules to raise the consumption tax rate from $5 \%$ to $8 \%$ in 2014 and $10 \%$ in 2015 , we assume that the consumption tax rate is set at $8 \%$ in 2014 and 10\% after 2015. Based on Hayashi and Prescott (2002) updated by Hansen and İmrohoroğlu (2011), we set the capital tax rate $\tau_{a, t}$ at $35 \%$.

\footnotetext{
${ }^{14}$ The pension fund includes Kokumin Nenkin, Kosei Nenkin Hoken, and three types of Kyosai Nenkin. For details, see http://www.mhlw.go.jp/topics/nenkin/zaisei/04/(in Japanese).

${ }^{15}$ More precicely the rate of return was $2.16 \%$ in $2002-2011$ and it was $0.63 \%$ in $2006-2011$ due to the global financial crisis. For details, see "Nenkin tsumitatekin unyou houkokusho" by the Ministry of Health, Labour and Welfare, 2011.
} 
Labor tax rate $\tau_{l, t}$ is set at $10 \%$ to match the tax revenue in the model with the data. ${ }^{16}$ In addition to the consumption tax, capital tax and labor tax, we levy a lump-sum tax $\tau_{l s}$ on each individual to match the total tax revenues in 2010, 78.6 trillion yen.

Government expenditures: We assume that the general government expenditure per capita $g_{i, j, e, t}$ is age-independent, and grows with the TFP growth rate. Total general government net expenditures, which consists of central government expenditure, local government expenditure and social security funds, in 2010 are 77.6 trillion yen.

Transfers: The transfers $t r_{i, j, e, t}$ are also assumed to be age-independent and redistributed as lump-sum manner. Total transfer (excluding pension benefits) $T R_{t}$ in 2010 is 18.2 trillion yen. ${ }^{17}$ The transfers include, in addition to social security benefits in cash, unfunded employee social benefits and social assistance benefits.

Government budget balance during the transition: Under the current public pension system in Japan, the government transfers a part of tax revenues to public pension budget for the purpose of supporting the basic pension system, which is represented as $X_{t}$ in equation (2). More concretely, a half of the total benefit expenditures of the basic pension is supported by the tax transfer. Thus we set $X_{t}$ at $1 / 2$ of the the basic pension expenditures. Because the premium $P R_{t}$, contribution from the general government budget $X_{t}$, and the payment of the public pension benefit $P_{t}$ are settled, the reserve fund dynamics is endogenously determined from equation (2). In the equation, the reserve funds $F_{t+1}$ will adjust to absorb the gap between the contribution

\footnotetext{
${ }^{16}$ Gunji and Miyazaki (2011) show that average marginal tax rates on labor incomes in Japan range from $14 \%$ to $21 \%$. However the total tax revenue from labor income becomes larger than actual value in 2010 if we use the labor tax rate of $20 \%$, because a large number of workers pay less due to tax deduction and exemption.

${ }^{17}$ Adding the pension benefits $P_{t}$ of 49.0 trillion yen, the total transfer is 67.2 trillion yen.
} 
and the benefit before it reaches zero. In case the fund runs out and reaches the floor, the deficit will be financed by the general government budget through the change in $X_{t}$.

Because tax revenues $T_{t}$, government expenditures $G_{t}$, transfers to individuals $T R_{t}$ and reserve fund $F_{t}$, which is nested in the general government budget, are determined in equation (1), we can compute the Japanese government bond path in the future.

\subsection{Technology}

Due to the partial equilibrium setting explained above, we can determine the real interest rate for private savings $r_{a, t}$ and the real wage growth rate $g_{t}^{w}$ seperately. We assume that the interest rate on individuals' saving is $3 \%$ on an annual basis, which is the average of the return on the government bond of $1 \%$ and the return on private capital of $4 \%$, using the weight of the size of the total capital and the outstanding government bond. ${ }^{18}$

We assume the wage growth rate of $1.5 \%$, based on the historical average of the total factor productivity growth rate. ${ }^{19}$ Note that the assumption on the wage growth rate of $1.5 \%$ is crucial to decide whether the macroeconomic slide works. Both the interest rate and the wage growth rate do not change over the simulation period between 2010 and 2100. In section 6 we run sensitivity analysis on the interest rate and growth rate.

\subsection{Consumption profiles}

From the complete market assumption, an individual's consumption at age $i$ is determined by equation (3), in particular $\widetilde{\lambda}_{i}$, as in Attanasio et al. (2007). We

\footnotetext{
${ }^{18}$ Sakuragawa and Hosono (2010) discuss fiscal sustainability of Japan from the relationship between the interest rate and GDP growth rate.

${ }^{19}$ We assume the Cobb-Douglas production function $Y_{t}=K_{t}^{\alpha}\left(A_{t} L_{t}\right)^{1-\alpha}$ with the capital ratio $\alpha$ is set at 0.38 . The TFP growth rate is $2.3 \%$ in $1981-2011$ and $1.2 \%$ in $2000-2011$.
} 
match the individuals' consumption profile in the model with the empirical one, which is typically hump-shaped over life cycle.

Generally the consumption differs among cohorts even if the different cohorts are the same age, and it may be affected by business cycles. We remove such cohort and year effects following the approach by Aguiar and Hurst (2009). To estimate the consumption profile controlled by the cohort and year effects, we use the Family Income and Expenditure Survey (FIES) by the Ministry of Internal Affairs and Communications. The FIES is a monthly diary survey which collects earnings, income and expenditures of Japanese households. ${ }^{20}$

Following Aguiar and Hurst (2009), we run the following regression:

$$
\ln C_{i t}=\beta_{0}+\beta_{\text {age }} D_{i t}^{\text {age }}+\beta_{c} D_{i t}^{\text {cohort }}+\beta_{t} D^{\text {time }}+\beta_{\text {fam }} \mathbf{X}_{i t}+\epsilon_{i t}
$$

with imposing on $\sum_{t=1981}^{2008} \beta_{t}=0$ and $\sum_{t=1981}^{2008} t \beta_{t}=0$. $\mathbf{X}_{i t}$ represents a vector of household characteristics such as a gender dummy, a marital status dummy, the number of adults, and the number of children. A vector of age dummies $D_{i t}^{\text {age }}$ represents adult-equivalent consumption profile over life cycle.

After deriving the adult consumption profile $\widetilde{\lambda}_{i}$, using the number of children at each age $d_{t, \tilde{i}}$ implied by the current fertility rates and adult consumption equivalence of dependent children $\nu$, we obtain the age-profile of individuals in the model $\lambda_{i}$. Figure 6 shows the age dummies $D_{i t}^{\text {age }}$ and smoothed profiles of adult consumption between 20 and 95 .

\footnotetext{
${ }^{20}$ For details, see appendix B.
} 


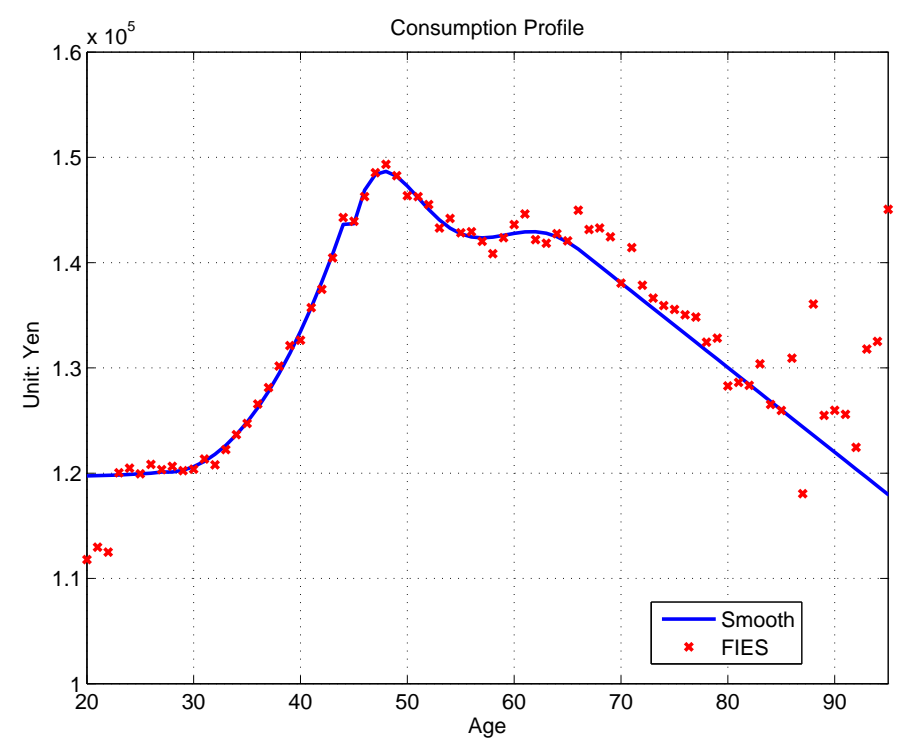

Figure 6: Approximated consumption profile

Table 1: Parameters of the model

\begin{tabular}{|lll|}
\hline Parameter & Description & Values/source \\
\hline \multicolumn{2}{|l|}{ Demographics } & \\
$\left\{\phi_{i, t}\right\}_{j=1}^{J}$ & fertility rates & IPSS (2012) \\
$\left\{\pi_{j}\right\}_{j=1}^{J}$ & conditional survival probabilities & IPSS (2012) \\
$J$ & maximum age & 110 years old \\
$I_{A}$ & adult age & 20 years old \\
\hline Labor market & \\
$\left\{y_{i, j, e, t}\right\}$ & earnings & Figure 5 \\
\hline Technology & & \\
$r_{a}$ & return on savings & $3 \%$ \\
$g^{w}$ & TFP and wage growth rate & $1.5 \%$ \\
\hline$G o v e r n m e n t$ & \\
$\tau_{l}$ & labor income tax & $10 \%$ \\
$\tau_{c}$ & consumption tax & $5 \%$ (in 2010) \\
$\tau_{a}$ & capital income tax & $35 \%$ \\
$\tau_{p}$ & pension contribution & see text \\
$r_{b}$ & interest rate on government debt & $1 \%$ \\
$r_{f}$ & return on pension fund asset & $2 \%$ \\
$I_{R, b}, I_{R, e}$ & full retirement age & see text \\
\hline
\end{tabular}




\subsection{Benchmark economy}

Our calibration strategy is to use Japanese micro data, demographics, and current pension rules and use our model to target the main economic indicators for the calendar year 2010. We do not target 2011 because of the very tragic triple disaster and the surrounding economic efforts to deal with the aftermath. Once we fine tune our model and produce the actual 2010 macroeconomic indicators, we will simulate the economy forward till 2100.

\section{$5 \quad$ Numerical results}

In this section, we provide forecasts of future paths of net government bonds and the pension fund, $\left\{F_{t}, B_{t}\right\}_{t=2010}^{2060}$, and other endogenous macroeconomic indicators given exogenous demographics, government expenditures, and estimated consumption and hours behavior in Japan. We would like to emphasize that our analysis is an accounting exercise, taking behavior as exogenous and estimated from micro data. We make this choice in order to gain on the side of heterogeneity, complexity and realism in how we represent the details of the Japanese economic agents and current law as applied to pensions.

Therefore, the main thrust for our modeling strategy is to develop a large and realistic measuring device to quantify which aspects of the macroeconomy are important in helping Japan achieve fiscal balance.

After we complete this accounting exercise, we plan to dial back the size of the state space and allow individuals to endogenously make their consumption-saving and labor supply decisions. Only in this general equilibrium framework can we identify which government economic policies can induce the private sector to behave in a way that helps Japan achieve fiscal balance in the future. 


\subsection{Benchmark transition}

In our accounting model, the projected demographic transition and future policy actions drive the labor market dynamics and related macroeconomic indicators. In particular, the time path of total population and working age population are shown in Figure 7.

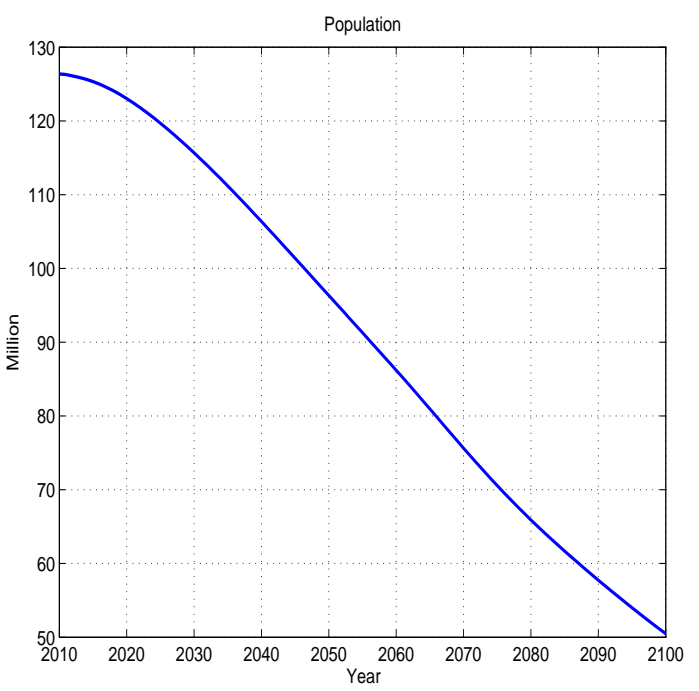

(a) Total Population
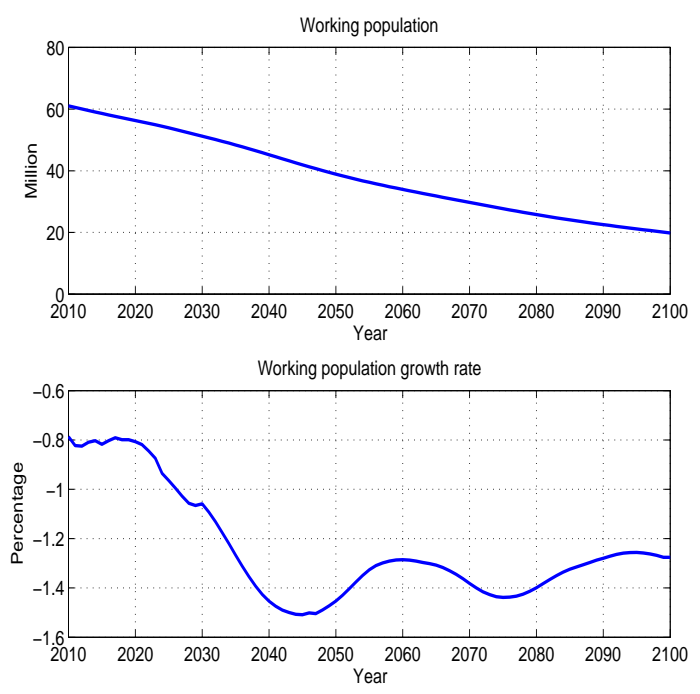

(b) Working Age Population

Figure 7: Projected Demographics: 2010-2100

For most of the years between 2010 and 2100, the rate of decline in the working age population is higher than $1 \%$ but less than $1.5 \%$ for most of the period between 2010 and 2100. The rate of decline of the population (not displayed) is smoother and less than that for the working age population.

We mention the population dynamics because the behavior of GDP and GDP per capita are driven by demographics in our accounting model. 


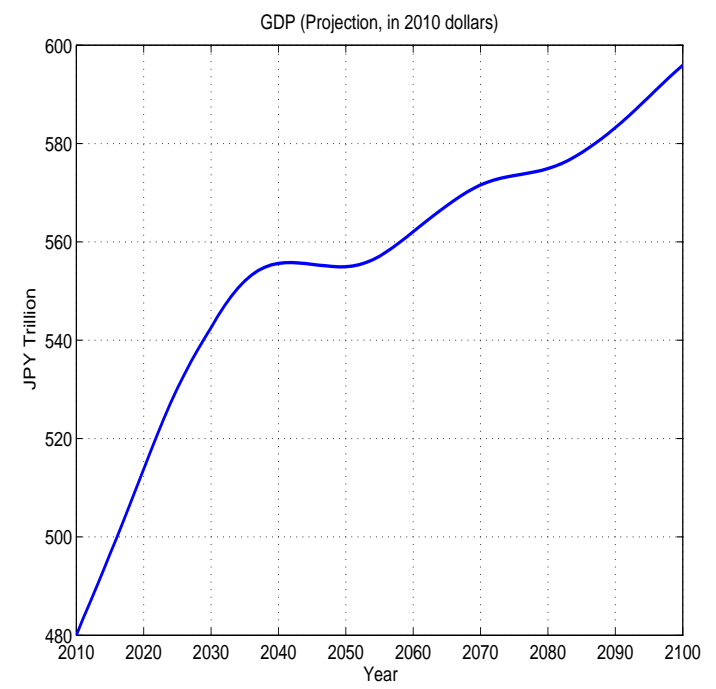

(a) GDP
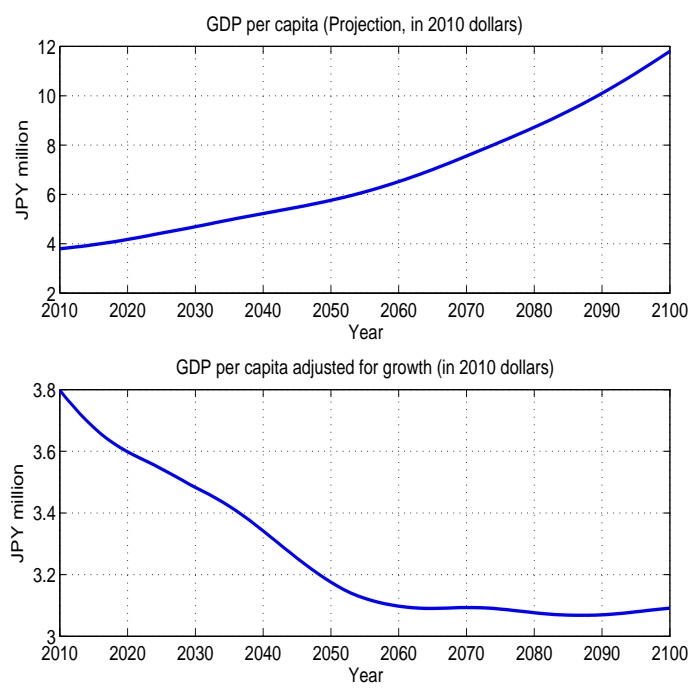

(b) GDP Per Capita

Figure 8: Projected GDP: 2010-2100

According to Figure 8, GDP per capita rises at 1.5\% annually, consistent with our 'balanced growth' assumption of $g_{t}^{w}=1.5 \%$ growth in the average real wage.

Total GDP, on the other hand, is the product of GDP per capita and total population whose growth rate is negative and changes over time and makes the growth rate of GDP always positive but slower than $1.5 \%$ per year.

We now display our model's forecasts of debt to GDP ratio. Figure 9 below depicts the net debt to GDP ratio, using two alternative definitions of debt. The first frame defines net debt as publicly held net debt net of the pension fund. This construct is directly comparable to the publicly held net debt in United States and other OECD countries. The second frame ignores the pension fund and may be the more familiar definition. 

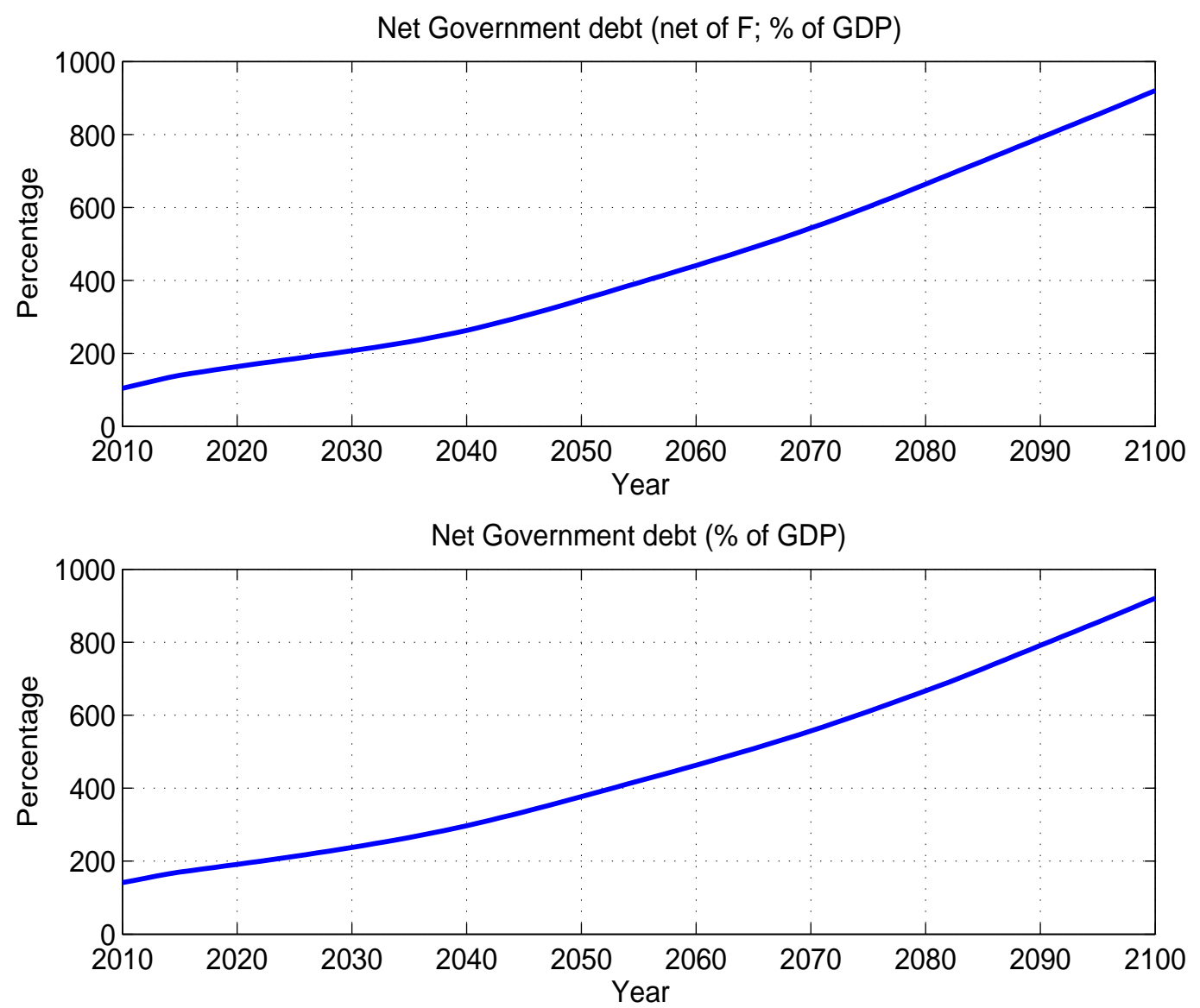

Figure 9: Net Debt and Net Debt to GDP Ratio

According to Figure 9, the ratio of net debt to GDP, $\left(B_{t}-F_{t}\right) / Y_{t}$ will reach $164.0 \%$ in $2020,206.4 \%$ in $2030,259.8 \%$ in $2040,340.3 \%$ in 2050 , and, $429.6 \%$ in 2060 when demographic projections end.

As the second frame of Figure 9 shows, when the pension fund is excluded, the debt to GDP ratio is just under 200\% in 2020; it is almost 300\% in 2040, reaching $462.9 \%$ in 2060 .

It is difficult to evaluate these numbers in the absence of a theory of debt that would have provided some insight. However, such theory does not exist 
yet, and we can only compare these enormous debt levels to recent experiences of debt-ridden economies. When international bond markets started to dump Greek bonds, their debt to GDP ratio was around 150\%; now the Greek debt to GDP is even higher at about $170 \%$ even though there have been substantial haircuts and outright default.

Of course, Japan is very different from Greece; it is a very large advanced economy. Most of the Japanese debt is held by Japanese individuals and institutions (more than 92\%) and they seem to continue to demand Japanese Government Bonds (JGBs) despite very low yields. Our model, like others in the literature, is silent on what a dangerous threshold is for this ratio. Our simulations indicate that the ratio can go near $300 \%$ in 2045 if there is no change in current policy and demographic projections. Below, we will examine the main contributors to the explosion in the debt to GDP ratio.

Consider net new borrowing (as a ratio to GDP) given by

$\frac{\left(B_{t+1}-F_{t+1}\right)-\left(B_{t}-F_{t}\right)}{Y_{t}}=\frac{\left(G_{t}+T R_{t}-T_{t}\right)}{Y_{t}}+\frac{\left(P_{t}-P R_{t}\right)}{Y_{t}}+\frac{\left(r_{b, t} B_{t}-r_{f, t} F_{t}\right)}{Y_{t}}$.

Above, we express net borrowing requirement (as a percentage of GDP) as coming from three distinct sources: (1) government purchases and transfer payments other than pensions, (2) burden on the budget from the pension deficit, and, (3) net interest paid on net government bonds (net of the pension fund returns).

Figure 10 shows this first decomposition of net borrowing. 


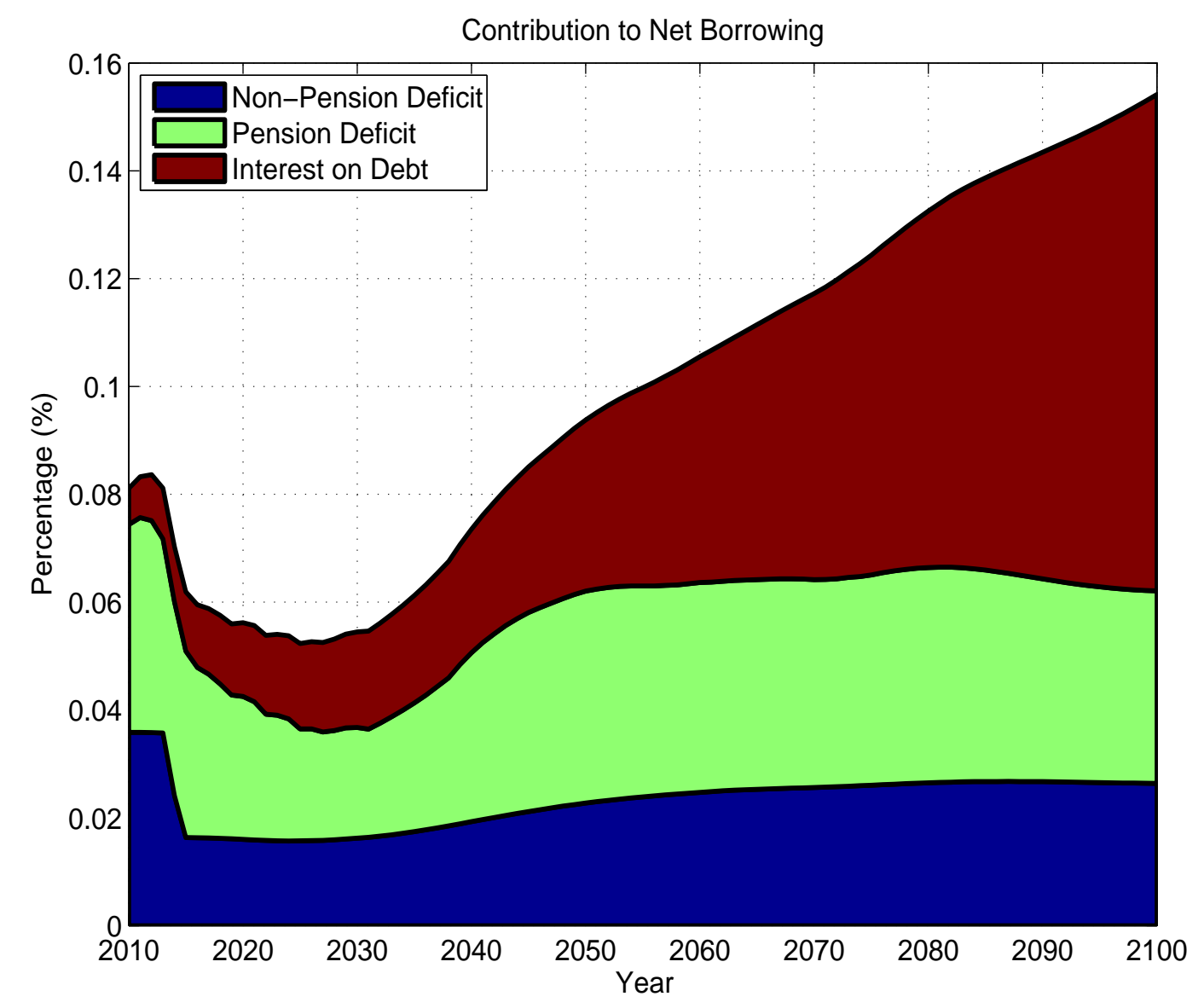

Figure 10: Sources of Net Borrowing

From Figure 10, we can highlight several key findings:

- Pension and non-pension deficits contribute about the same, just about 4 percentage points each, to new borrowing requirements over the next few years, with net interest on debt playing a much smaller role, thanks to the low real interest rate on JGBs in the current economic environment.

- With the consumption tax rate expected to rise from $5 \%$ to $10 \%$ in 2014-2015, there is a significant improvement in the non-pension deficit and then a gradual rise over time as non-pension transfers and health 
expenditures start to rise.

- There is an initial, significant decline, and later, a smooth decline in the pension deficit. However, in about 25 years the pension deficit starts to rise again, eventually stabilizing at about $3.5 \%$ annually.

- Net interest payments on JGBs eventually dominate net borrowing requirements despite the low $1 \%$ interest rate; the stock of debt is just too large.

In Japan, the government uses general tax revenues to finance $50 \%$ of the total basic pension benefits. Below, we will provide an accounting of the net borrowing requirement with this alternative classification of government accounts.

$$
\frac{\left(B_{t+1}-B_{t}\right)}{Y_{t}}=\frac{\left(G_{t}+T R_{t}+F_{t}-T_{t}\right)}{Y_{t}}+\frac{\left(P_{t}-P R_{t}-X_{t}\right)}{Y_{t}}+\frac{r_{b, t} B_{t}}{Y_{t}} .
$$

Figure 11 shows this decomposition of net borrowing. 


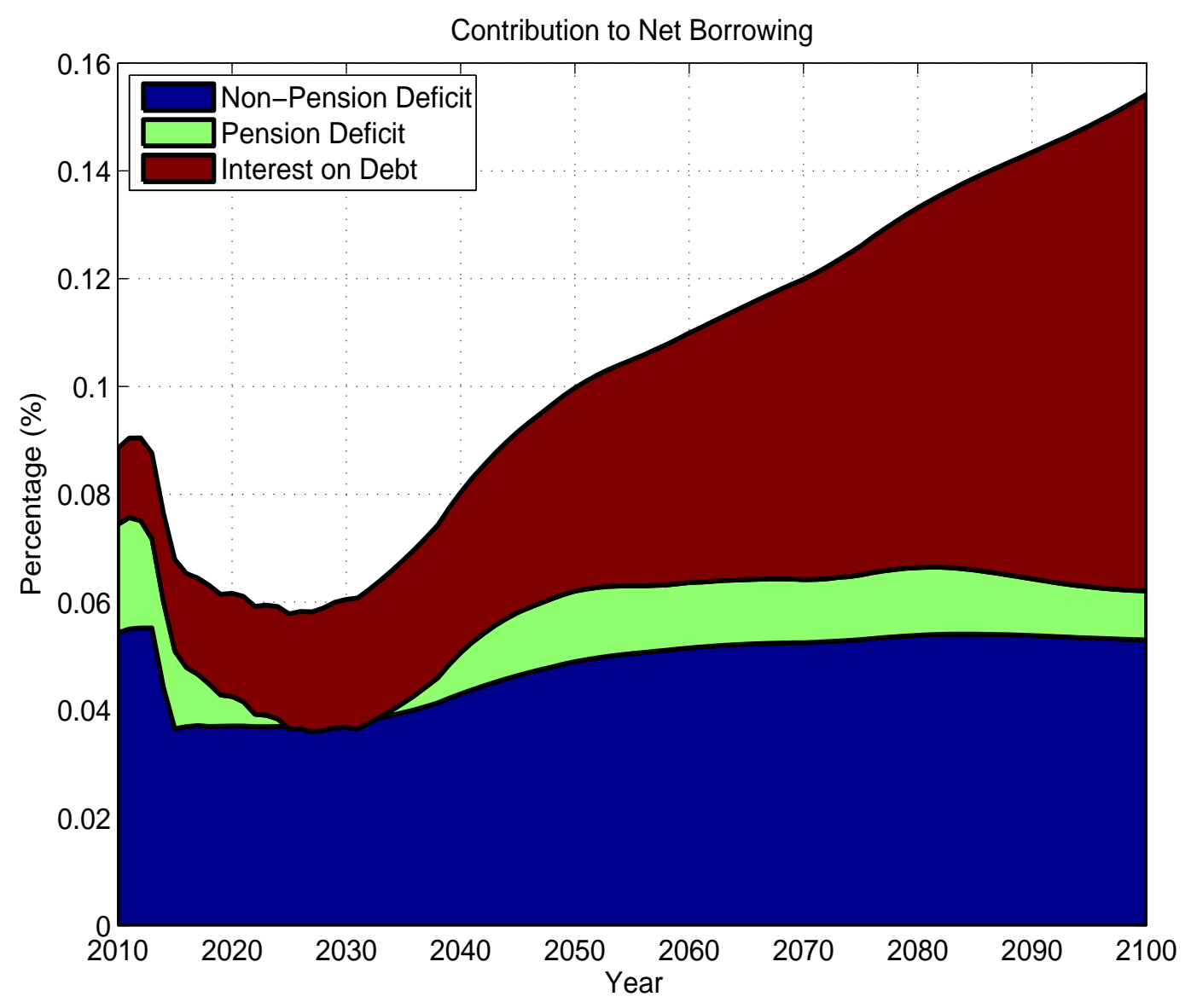

Figure 11: Sources of Borrowing

Note that the above decomposition simply shifts the burden of pension payments onto the non-pension side of the government primary deficit. In other words, Figure 11 portrays a very rosy picture of public pensions and an equally depressing picture of non-pension budgetary items.

Now that we have presented some basic accounting, we can now dig deeper into the components and explore the factors behind the rise in the debt to GDP ratio.

Figure 12 shows the time path of major government accounts: (i) purchases 
of goods and services as a ratio to GDP, (ii) non-pension transfer payments to GDP ratio, (iii) the ratio of total pension payments to GDP, (iv) the ratio of government's $50 \%$ contribution toward basic pension payments to GDP ratio, (v) the ratio of tax revenues to GDP, and, (vi) the ratio of total pension premiums to GDP.

In the first frame of Figure 12, we observe a nearly 4 percentage point increase in the ratio of government purchases to GDP. The main reason for this increase is our assumption that the numerator increases at the rate of real wage growth, $1.5 \%$, but real GDP rises slower due to the decline in the population. Once population dynamics stabilize around 2060, this ratio also stabilizes. However, until then, government purchases imposes a significant burden on government finances. Any reform that would reduce the projected growth of government purchases, for example in public health expenditures, would reduce the fiscal pressures to raise taxes to slow down the need to borrow from the public.

The second frame of Figure 12 shows the ratio of (non-pension) transfer payments to GDP. Once again, GDP rises more slowly than non-pension transfers, and the additional burden introduced by this increase is about an annual $1 \%$ of GDP in terms of new borrowing. 

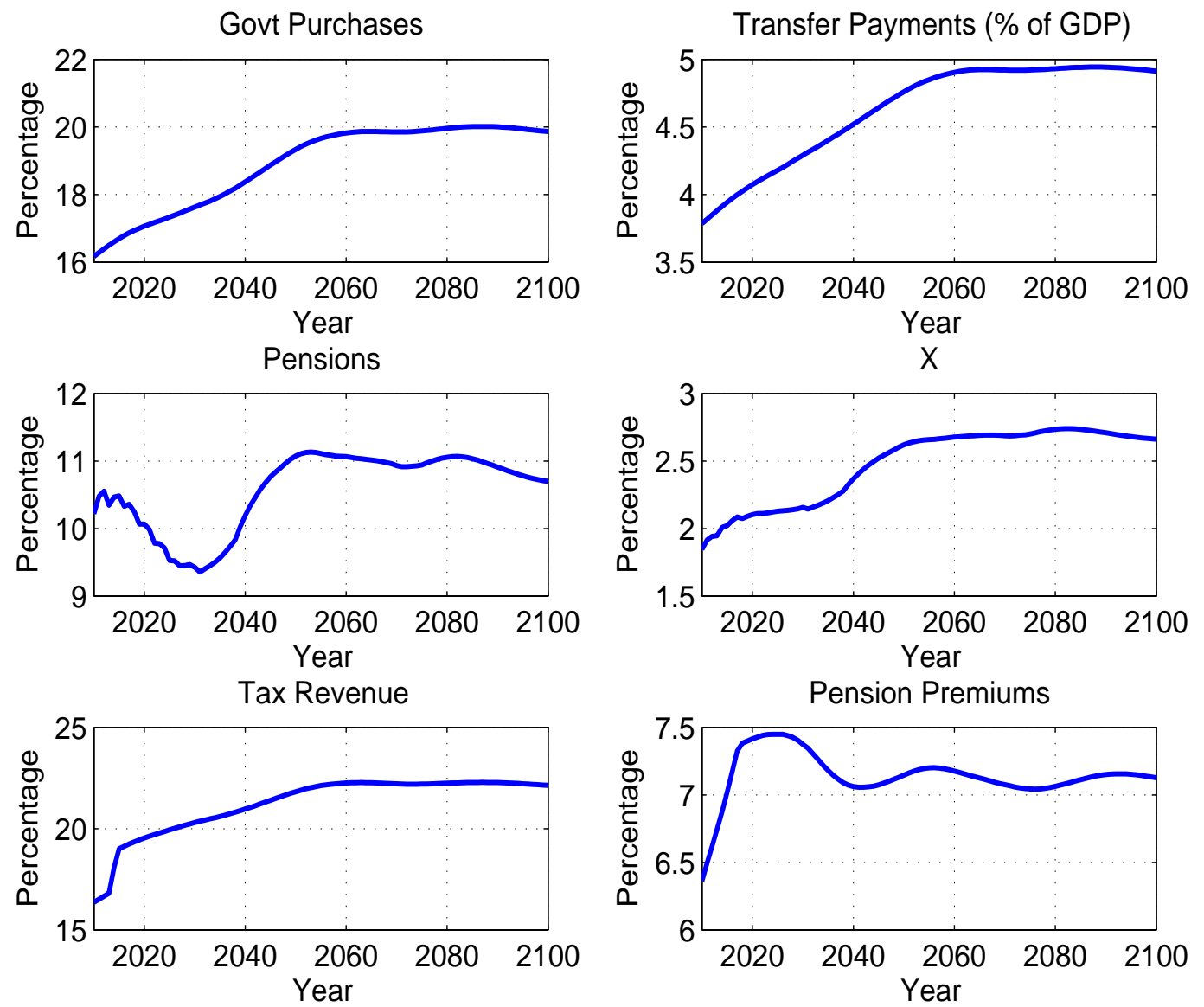

Figure 12: Government Purchases of Goods and Services

Pension payments, on the other hand, create a significant burden on the budget despite the macroeconomic slide. In the third frame of Figure 12, the ratio of total pensions to GDP falls by about 1 percentage point due to the macro slide, but once the macro slide ends, it rises very fast to around $11 \%$ of GDP. Clearly, pension reform would have to be a part of any fiscal policy package that deals with bringing about fiscal sustainability. A related figure is depicted in the fourth frame as the payment out of general tax revenues made by the government. This payment amounts to half of total basic pension 
payments. Despite the macroslide, the Japanese government has to use a significant fraction of resources to finance total pension payments, over and above what the pension premiums can finance.

How are the tax revenues projected to deal with these large expected government expenditures? In the fifth frame of Figure 12, the ratio of tax revenues (excluding pension premiums) to GDP is projected to rise significantly due to the expected rise in the consumption tax in 2014-2015. After then, per capita tax revenues (that include capital income tax revenues and lump sum taxes that represent import taxes and duties) are assumed to rise at the same rate as the tax base, which is increasing at the growth rate of real wages (1.5\%), while GDP rises slower as the population shrinks. Once again, as demographic transition converges by 2060 , so does this ratio.

Finally, the sixth frame in Figure 12 displays the ratio of total pension premiums collected to GDP. As the contribution rate is projected to rise from $16.058 \%$ in 2010 by $0.354 \%$ every year to $18.3 \%$ in 2017 , this ratio reaches a peak of nearly $7.5 \%$ of GDP, and eventually settles around $7 \%$ of GDP.

Figure 12 suggests that taking a closer look at reforms in the health expenditure area could yield significant relief to the projected budget deficits. As total GDP grows at a rate less than the growth of real wages and productivity $\left(g_{t}^{w}=1.5 \%\right)$, due to the decline in population, government purchases will become a larger burden on the budget over time. Our model predicts an eventually permanent $3.5 \%$ increase in the ratio of government purchases to GDP. If taxes are not raised to finance this increase, the annual burden of about $3.5 \%$ would add to the government debt.

The detailed government accounts displayed in Figure 12 suggests that there are three avenues to achieve fiscal balance: (i) $G_{t}$ must be contained and the near- $4 \%$ of GDP increase prevented, (ii) $T_{t}$ must be raised further, perhaps by enlarging the tax base and the number of taxpayers, and (iii) the pension deficit must be reduced.

We now look more closely at the Japanese pension program. As the population ages, there are increasing numbers of retirees receiving pension. At the 
same time, the 'macroeconomic slide' works to reduce the replacement rate as shown in Figure 13 below. Retirees experience a decline in the fraction of income their pensions replace from $60 \%$ to about $42 \%$.

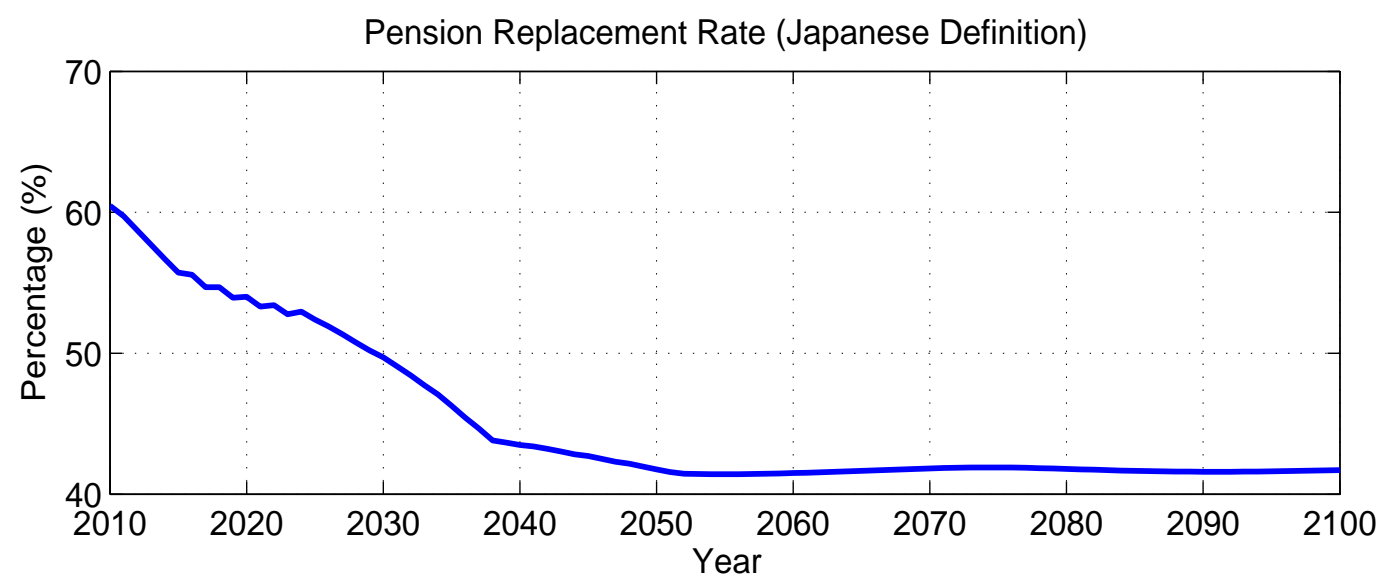

Pension Replacement Rate (type 2 male: standard definition)

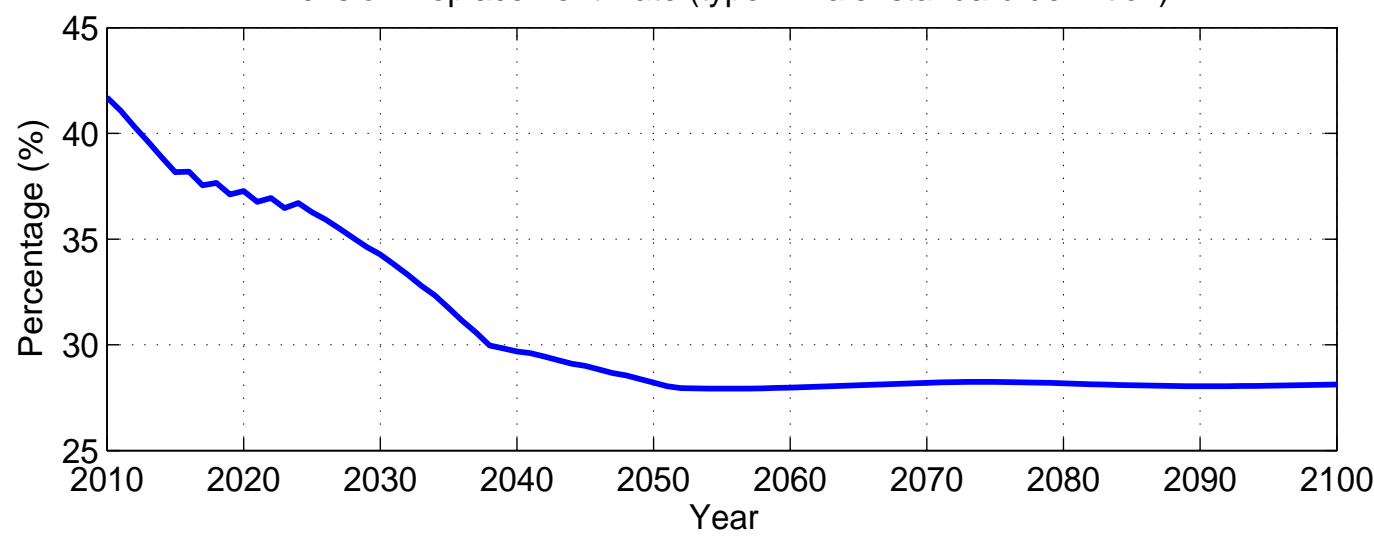

Figure 13: Total Pension Premiums Collected

Figure 13 shows the projected pension replacement rates using two definitions. In the first frame, the ratio of a household's pension (husband's pension plus housewife's basic pension) to the husband's earnings is shown. With the macroeconomic slide in effect, the replacement rate falls from $60 \%$ to about $42 \%$. Using a different definition, where the replacement rate is taken as the 
ratio of a type 2 male (a male with a regular employment) to the cross sectional average earnings of a type 2 male, we again see a significant reduction from above $41 \%$ to about $28 \%$. Although there is a significant increase in the number of retirees after 2010, the 'macroeconomic slide' reduces the average pension per retiree and therefore there is not much change in the ratio of total pensions to GDP.

The impact of these projections on the pension fund can be seen in Figure 14

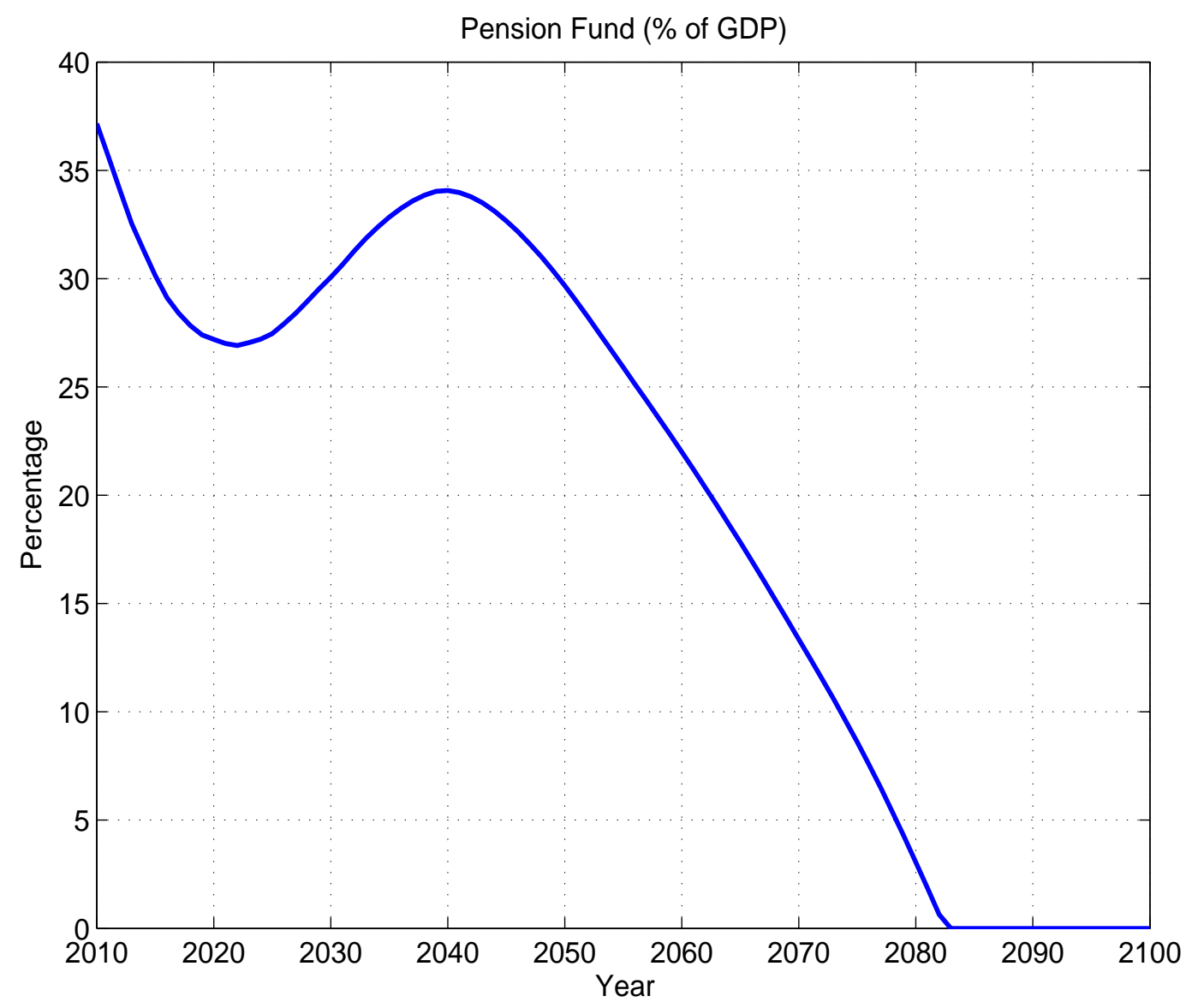

Figure 14: Pension Deficit 
Since the pension balance is negative and significant at about $4 \$$ in 2011 , the pension fund begins its steep decline from about $36 \%$ or GDP to about $25 \%$ of GDP. The pension deficit declines as higher premiums are collected and lower per capita benefits are distributed to pensioners (due to the macroeconomic slide). As a result, the pension deficit falls below $2 \%$ in early 2020 s. Since $50 \%$ of total pensions are paid for from general tax revenues, this reduction in the pension deficit allows for an accumulation of the fund, at least until about 2040. The pension deficit rises back to its older and higher levels and settles around $3.5 \%$ and this restarts the decumulation of the fund toward below $20 \%$.

\section{Sensitivity}

No Macroeconomic Slide How important is the macro slide introduced in 2004 and amended since then? Figure 15 shows the pension fund under the counterfactual assumption that the pension rules follow pre-2004 arrangements and ignore the reforms of the macro slide. 


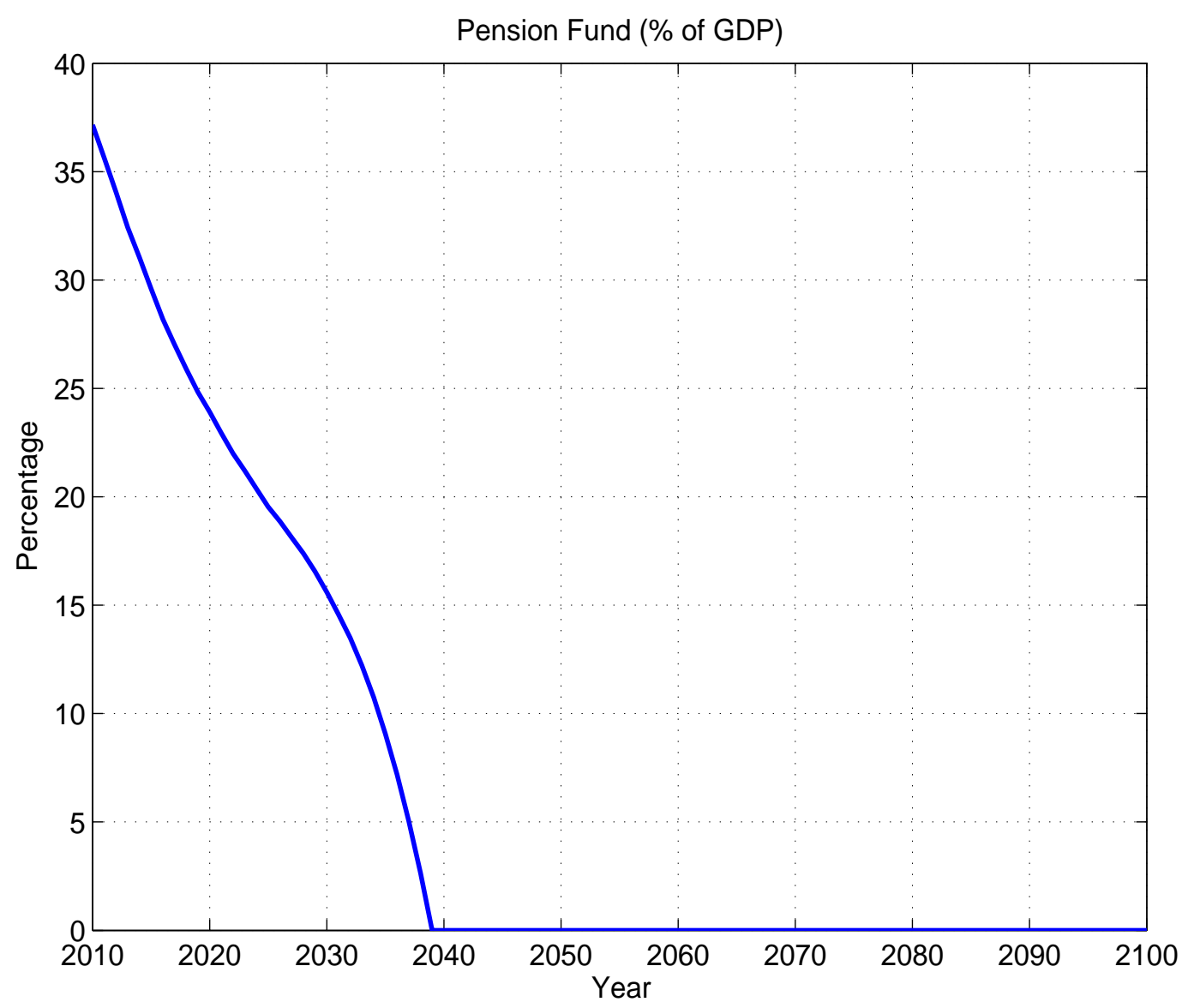

Figure 15: Pension Fund

Without any significant reductions in pension benefits or increases in premiums, the pension fund is very quickly depleted and disappears before 2040 . This counterfactual simulation highlights the quantitative significance of the macro slide in containing the burden of pensions on the government budget.

Productivity Growth In our baseline simulation, we assume a real wage growth rate of $1.5 \%$, in part to be consistent with official forecasting in calculating future pension benefits and premiums. Below, we present alternative results that assume growth rates of $0.5 \%$ and $2.5 \%$ instead. 
Table 2: Effects of Different Wage Growth Rates on Fiscal Sustainability

\begin{tabular}{rrcr}
\multicolumn{4}{c}{$\frac{\left(B_{t}-F_{t}\right)}{Y_{t}}$} \\
\hline & $g_{t}^{w}=0.5 \%$ & Baseline $\left(g_{t}^{w}=1.5 \%\right)$ & $g_{t}^{w}=2.5 \%$ \\
\hline 2010 & 1.042 & 1.042 & 1.042 \\
2020 & 1.877 & 1.640 & 1.425 \\
2030 & 2.712 & 2.076 & 1.566 \\
2040 & 3.845 & 2.632 & 1.758 \\
2050 & 5.524 & 3.471 & 2.129 \\
2060 & 7.572 & 4.411 & 2.513 \\
\hline
\end{tabular}

In Table 2, a higher real wage growth of $2.5 \%$ allows for a longer period of time until debt to GDP ratio goes above $200 \%$ as tax revenues grow faster than the benchmark case. Still, the fiscal balance is not achieved with debt to GDP ratio at historically unprecedented highs.

On the other hand, slower growth, such as a $0.5 \%$ real wage growth, brings the fiscal day of reckoning much faster, and makes the case for fiscal reform urgent. The ratio of debt to GDP goes over $200 \%$ in 2022 . The growth rate of real GDP in Japan has been below $2.5 \%$ over the last two decades and this table suggests that unless a growth miracle occurs, policymakers should not count on significant increases in tax revenues coming from faster economic growth and hence larger tax base due to growth.

In order to see how growth affects the decomposition of the budget deficit into components, consider Table 3 below. 
Table 3: Wage Growth on Sources of Borrowing

\begin{tabular}{|c|c|c|c|}
\hline & $g_{t}^{w}=0.5 \%$ & Baseline $\left(g_{t}^{w}=1.5 \%\right)$ & $g_{t}^{w}=2.5 \%$ \\
\hline & \multicolumn{3}{|c|}{$\frac{\left(G_{t}+T R_{t}-T_{t}\right)}{Y_{t}}$} \\
\hline 2010 & 0.0396 & 0.0363 & 0.0315 \\
\hline 2020 & 0.0198 & 0.0164 & 0.0124 \\
\hline 2030 & 0.0202 & 0.0165 & 0.0129 \\
\hline 2040 & 0.0235 & 0.0195 & 0.0160 \\
\hline 2050 & 0.0272 & 0.0228 & 0.0195 \\
\hline \multirow[t]{2}{*}{2060} & 0.0292 & 0.0247 & 0.0215 \\
\hline & \multicolumn{3}{|c|}{$\frac{\left(P_{t}-P R_{t}\right)}{Y_{t}}$} \\
\hline 2010 & 0.0395 & 0.0386 & 0.0376 \\
\hline 2020 & 0.0354 & 0.0253 & 0.0186 \\
\hline 2030 & 0.0331 & 0.0186 & 0.0099 \\
\hline 2040 & 0.0452 & 0.0289 & 0.0201 \\
\hline 2050 & 0.0551 & 0.0364 & 0.0265 \\
\hline \multirow[t]{2}{*}{2060} & 0.0561 & 0.0354 & 0.0252 \\
\hline & \multicolumn{3}{|c|}{$\frac{\left(r_{b, t} B_{t}-r_{f, t} F_{t}\right)}{Y_{t}}$} \\
\hline 2010 & 0.0067 & 0.0067 & 0.0067 \\
\hline 2020 & 0.0161 & 0.0136 & 0.0115 \\
\hline 2030 & 0.0249 & 0.0174 & 0.0121 \\
\hline 2040 & 0.0369 & 0.0222 & 0.0131 \\
\hline 2050 & 0.0552 & 0.0303 & 0.0165 \\
\hline 2060 & 0.0757 & 0.0396 & 0.0201 \\
\hline
\end{tabular}

Table 3 presents a detailed accounting of the reason for the debt the GDP ratio to increase. In 2010, non-pension budget deficit contributes $44.5 \%$ of the net borrowing requirement, which amounts to $3.63 \%$ of GDP. Pension deficit 
creates a similar fiscal burden, $47.3 \%$ of the total for 2010 , which is $3.86 \%$ of GDP. The burden of net interest on government's net debt is only $0.67 \%$ of GDP. The total net borrowing requirement in 2010 is $8.16 \%$ of GDP.

According to Table 3, slower real wage growth primarily affects the pension budget deficit. When the labor income tax base grows slower than that in the benchmark simulation, total pension premiums and taxes collected decrease, creating a larger deficit and net borrowing requirement. The opposite is true with a higher real wage growth rate.

Slower or faster real wage growth has an indirect impact on the contribution of net interest payments on government debt to the net increase in debt. As the tax base grows slower than the benchmark case, there is a larger debt from higher pension and non-pension deficits. In addition, the reduction in the pension fund reduces the return the government makes on the fund. As a result, net interest paid on government's net debt eventually becomes the largest component in net borrowing by 2050 .

Table 4: Effects of Different Returns on the Pension Fund on Fiscal Sustainability

\begin{tabular}{rrrr}
\multicolumn{4}{c}{$\frac{\left(B_{t}-F_{t}\right)}{Y_{t}}$} \\
\hline & $r_{f, t}=1 \%$ & Baseline $\left(r_{f, t}=2 \%\right)$ & $r_{f, t}=3 \%$ \\
\hline 2010 & 1.042 & 1.042 & 1.042 \\
2020 & 1.671 & 1.640 & 1.605 \\
2030 & 2.137 & 2.076 & 2.001 \\
2040 & 2.732 & 2.632 & 2.497 \\
2050 & 3.616 & 3.471 & 3.252 \\
2060 & 4.596 & 4.411 & 4.089 \\
\hline
\end{tabular}

Returns on the Pension Fund Table 4 shows the net debt to GDP ratios for selected years for different assumptions on the return to the pension 
fund. Clearly, this has a very small impact on the overall net debt as the ratio of the pension fund to GDP is relatively small, and projected to decline in the future.

Returns on the Government Debt However, if the interest rate on government debt is higher than the $1 \%$ assumed for the benchmark case, the resulting impact on fiscal balance can be disastrous. For example, if the real interest rate on government debt is $3 \%$, then net debt to GDP ratio will become $200 \%$ in 2020 , and $300 \%$ in 2030 .

Table 5: Effects of Different Returns on Government Debt on Fiscal Sustainability

\begin{tabular}{rrrrrr}
\multicolumn{6}{c}{$\frac{\left(B_{t}-F_{t}\right)}{Y_{t}}$} \\
\hline & $r_{b, t}=-1 \%$ & $r_{b, t}=0 \%$ & Baseline $\left(r_{b, t}=1 \%\right)$ & $r_{b, t}=2 \%$ & $r_{b, t}=3 \%$ \\
\hline 2010 & 1.042 & 1.042 & 1.042 & 1.042 & 1.042 \\
2020 & 1.333 & 1.480 & 1.640 & 1.814 & 2.003 \\
2030 & 1.418 & 1.719 & 2.076 & 2.502 & 3.008 \\
2040 & 1.553 & 2.023 & 2.632 & 3.422 & 4.448 \\
2050 & 1.857 & 2.529 & 3.471 & 4.798 & 6.672 \\
2060 & 2.180 & 3.068 & 4.411 & 6.457 & 9.597 \\
\hline
\end{tabular}

On the other hand, a smaller real interest rate on government bonds reduces the fiscal burden. For example, if the interest rate is zero, then the $200 \%$ debt to GDP threshold is postponed for another decade. In addition, if Japan experiences inflation, and in particular, inflation in excess of the nominal interest rate of government bonds, then the decline in the real value of the stock of government bonds helps contain the fiscal problem for several decades. In this case, more moderate reform in expenditures or small increases in tax revenues may bring about fiscal sustainability. However, this case assumes a negative $1 \%$ real interest rate on JGBs for nearly a century and it is difficult 
to expect that Japanese bondholders would not demand better terms to hold this asset voluntarily.

Different Fertility Projections There are three versions of the fertility projections produced by IPSS: low, medium, and high variants. Table 6 shows the net debt to GDP ratios for selected years for the three variants of fertility projections. Higher fertility raises the relative share of working cohorts in the population and tends to improve fiscal balance. However, whichever variant happens to be realized, there is very little difference on the fiscal position of Japan. This may come as a surprise at first glance. However, an improvement in tax revenues as the tax base increases is nearly completely offset by similar increases in per capita expenditures, both during working years and also in retirement. As a result, higher or lower fertility has little impact on the net debt to GDP ratio, even in the long run.

Table 6: Effects of Different Fertility Projections on Fiscal Sustainability

\begin{tabular}{cccc}
\multicolumn{4}{c}{$\frac{\left(B_{t}-F_{t}\right)}{Y_{t}}$} \\
\hline & Low Fertility & Baseline Fertility & High Fertility \\
\hline 2010 & 1.042 & 1.042 & 1.042 \\
2020 & 1.636 & 1.640 & 1.643 \\
2030 & 2.052 & 2.076 & 2.101 \\
2040 & 2.597 & 2.632 & 2.671 \\
2050 & 3.505 & 3.471 & 3.441 \\
2060 & 4.620 & 4.411 & 4.226 \\
\hline
\end{tabular}

Different Survival Projections Table 7 displays the net debt to GDP ratios for selected years for low, medium, and high survival rate projections made by IPSS. Here, the impact on fiscal sustainability is even smaller. Longer 
lives raise the fiscal burden as the share of elderly in the society increases. However, the quantitative impact seems to be very small.

Table 7: Effects of Different Survival Projections on Fiscal Sustainability

\begin{tabular}{cccc}
\multicolumn{5}{c}{$\frac{\left(B_{t}-F_{t}\right)}{Y_{t}}$} \\
\hline & Low Survival & Baseline Survival & High Survival \\
\hline 2010 & 1.042 & 1.042 & 1.042 \\
2020 & 1.640 & 1.640 & 1.641 \\
2030 & 2.064 & 2.076 & 2.080 \\
2040 & 2.598 & 2.632 & 2.651 \\
2050 & 3.403 & 3.471 & 3.519 \\
2060 & 4.296 & 4.411 & 4.501 \\
\hline
\end{tabular}

\section{Experiments}

Pension rules The population is aging very rapidly in Japan and this is putting significant pressure on the pension system. If the government undertook additional pension reform, how much would this impact the debt to GDP ratio in the future? 
Table 8: Effects of Different Pension Rules on Fiscal Sustainability

\begin{tabular}{rrrrrr}
\multicolumn{7}{c}{$\frac{\left(B_{t}-F_{t}\right)}{Y_{t}}$} \\
\hline & & & $i_{R}=70$ and & Earnings \\
& & & $\begin{array}{r}\text { Benefit } \\
\text { Benefit }\end{array}$ & tax rate \\
& Baseline & $i_{R}=70$ & cut by $10 \%$ & cut by $10 \%$ & up by $5 \%$ \\
\hline 2010 & 1.042 & 1.042 & 1.042 & 1.042 & 1.042 \\
2020 & 1.640 & 1.624 & 1.518 & 1.504 & 1.637 \\
2030 & 2.076 & 2.003 & 1.824 & 1.759 & 1.947 \\
2040 & 2.632 & 2.381 & 2.223 & 1.998 & 2.286 \\
2050 & 3.471 & 2.930 & 2.855 & 2.367 & 2.864 \\
2060 & 4.411 & 3.577 & 3.553 & 2.803 & 3.497 \\
\hline
\end{tabular}

Table 8 summarizes the impact on Japan's net government debt to GDP ratio under significant pension reforms.

Raising the retirement age to 70 has a small effect in the short run, a larger effect in the long run, but still does not bring about a significant reduction in debt to GDP over the next $30+$ years. ${ }^{21}$ Just by itself, raising the retirement age from the current 65 to 70 is insufficient.

Cutting pension benefits by 10\% reduces debt to GDP (by reducing the pension deficit) more significantly. Similarly, raising the earnings tax rate on employers' pension part by 5 percentage points slows down the increase in debt to GDP ratio.

What seems to help the most is a combination of raising the retirement age to 70 and reducing benefits by $10 \%$. The debt to GDP ratio is still under $200 \%$ by 2040 under this combination of new pension rules.

\footnotetext{
${ }^{21}$ Raising the retirement age to 67 has very little impact in the short run, and only a minor effect by 2060 .
} 
The findings in Table 8 highlight the need to consider bolder reforms in the pension system.

Consumption Tax Table 9 displays the net debt to GDP ratio when the consumption tax is raised beyond $10 \%$, which is the current law and expectation. According to our simulations, there is very little impact on fiscal imbalance in the short run. Only when the consumption tax rate is raised to $20 \%$ can we see some reduction in the debt to GDP ratio in about $30-40$ years.

Table 9: Effects of Higher Consumption Tax Rates on Fiscal Sustainability

\begin{tabular}{cccc}
\multicolumn{4}{c}{$\frac{\left(B_{t}-F_{t}\right)}{Y_{t}}$} \\
\hline & $\tau_{c, t}=10 \%$ & $\tau_{c, t}=15 \%$ & $\tau_{c, t}=20 \%$ \\
\hline 2010 & 1.042 & 1.042 & 1.042 \\
2020 & 1.640 & 1.589 & 1.580 \\
2030 & 2.076 & 1.819 & 1.668 \\
2040 & 2.632 & 2.154 & 1.796 \\
2050 & 3.471 & 2.742 & 2.153 \\
2060 & 4.411 & 3.417 & 2.587 \\
\hline
\end{tabular}

A higher consumption tax reduces the non-pension deficit significantly. In fact, when it is raised to $20 \%$, the non-pension budget balance is actually positive and helps in reducing the overall net borrowing requirements. However, the pension deficit is untouched and these findings highlight the importance of pension reform or much higher levels of taxation or a combination of these policies in order to bring about fiscal sustainability to Japan.

Figure 16 displays the ratio of net debt to GDP under a consumption tax rate of $20 \%$. Despite a temporary slowdown, a 10 percentage point addition 
to the planned $10 \%$ consumption tax fails to bring about fiscal sustainability in the long run.
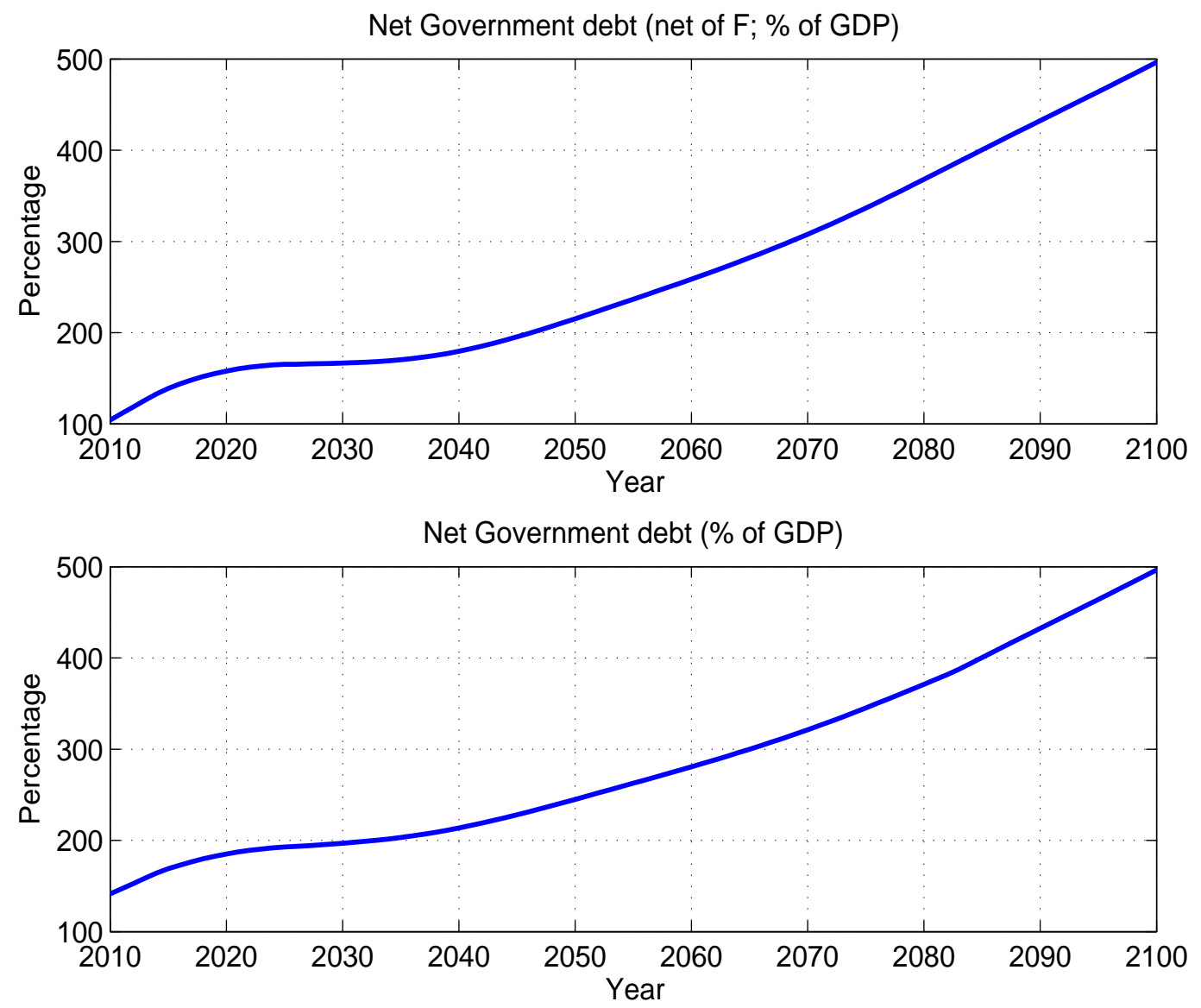

Figure 16: Pension Fund

The effect of a consumption tax rate of $20 \%$ on the pension fund is displayed in Figure 17. 


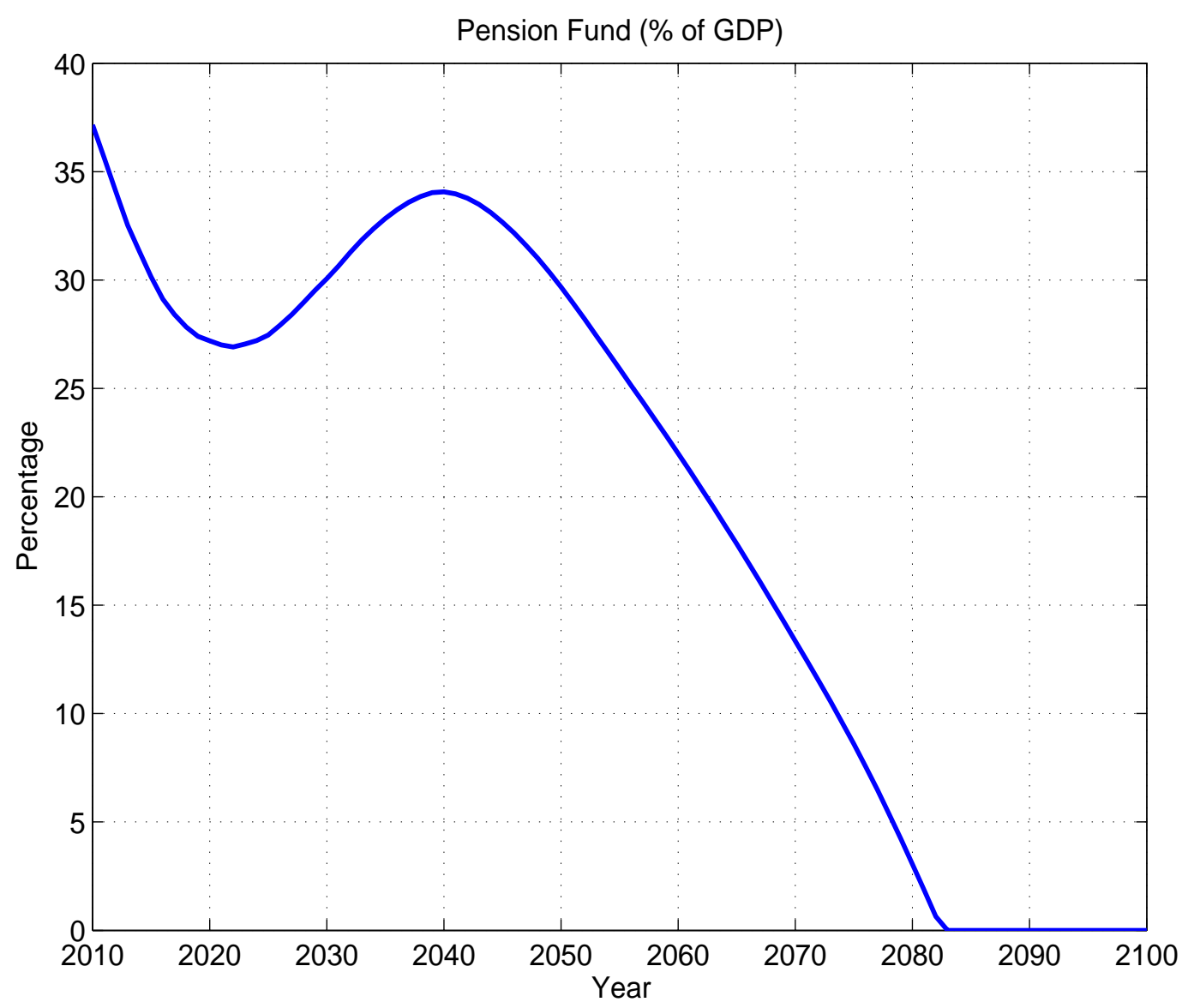

Figure 17: Pension Fund

A higher consumption tax delays the eventual depletion of the pension fund by about 40 years but cannot prevent it from eventually going to zero. We can now

In order to highlight the factors that cause the depletion of the pension fund and the continued increase in the debt to GDP ratio in the long run, consider Figure 18 which shows the decomposition of net borrowing requirements into pension, non-pension, and interest payment sources. 


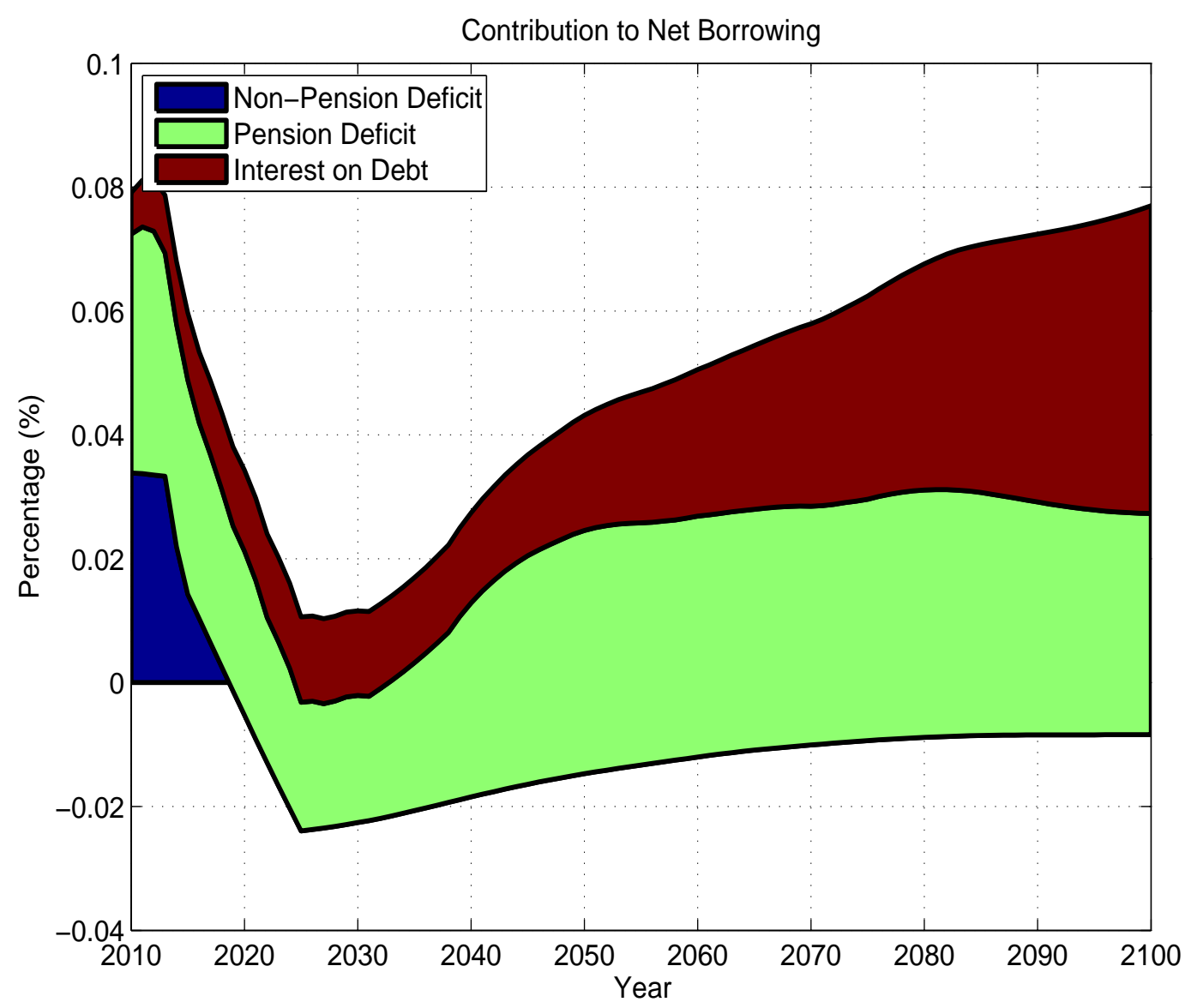

Figure 18: Sources of Net Borrowing Requirements

Figure 18 indicates that non-pension deficit is eliminated and turned into a small surplus. The pension deficit is unaltered, and, together with the increasing burden of interest payments, net debt to GDP ratio continues to rise out of control.

Female Labor Force Participation Female labor force participation (FLFP) in Japan is among the lowest in advanced OECD economies. In Table 10, we consider the effect of different FLFP rates on the net debt to GDP ratio. 
Below, scenario (A) assumes a rise in the average FLFP rates to those for males at each age holding unchanged the relative shares of employment as regular, irregular, and self, conditional on participation. Scenario (B) assumes a rise in the share of regular employment for females to the level of males, with no change in the average FLFP rate at each age. Finally, scenario (C) assumes that (A) and (B) occur simultaneously.

Table 10: Effects of Female Labor Force Participation on Fiscal Sustainability

\begin{tabular}{rrrrr}
\multicolumn{5}{c}{$\frac{\left(B_{t}-F_{t}\right)}{Y_{t}}$} \\
\hline & Baseline & FLFP (A) & FLFP (B) & FLFP (C) \\
\hline 2010 & 1.042 & 1.042 & 1.042 & 1.042 \\
2020 & 1.640 & 1.511 & 1.609 & 1.472 \\
2030 & 2.076 & 1.728 & 1.935 & 1.561 \\
2040 & 2.632 & 2.093 & 2.320 & 1.725 \\
2050 & 3.471 & 2.680 & 2.958 & 2.075 \\
2060 & 4.411 & 3.344 & 3.679 & 2.481 \\
\hline
\end{tabular}

Table 10 shows that a significant increase in the FLFP, especially under scenario (C), provides medium term relief to the fiscal burden. Indeed, the improvement in the debt to GDP ratio under scenario $(\mathrm{C})$ is greater than that under a consumption tax rate of $20 \%$.

It will be useful to make a more detailed comparison of a higher FLFP (C) and a higher consumption tax rate (20\%). Figure 19 displays the ratio of net debt to GDP under FLFP (C). Net debt to GDP grows more slowly compared to the benchmark simulation, and also relative to that in the case of a higher consumption tax. There are two reasons for the positive impact of higher labor force participation of females on fiscal sustainability.

First, the pension tax base is greatly increased, and the pension fund recovers almost immediately and rises continually. Figure 20 shows the monotonic 
increase in the pension fund to GDP ratio starting before 2020. Although females now receive larger total pensions that result from higher labor market earnings, they also contribute larger pension premiums on their employers' pension. Since the latter starts immediately, there is a significant relief to the pension budget. Eventually, the pension deficit grows to an annual of about $3 \%$, somewhat smaller than that in the benchmark case.
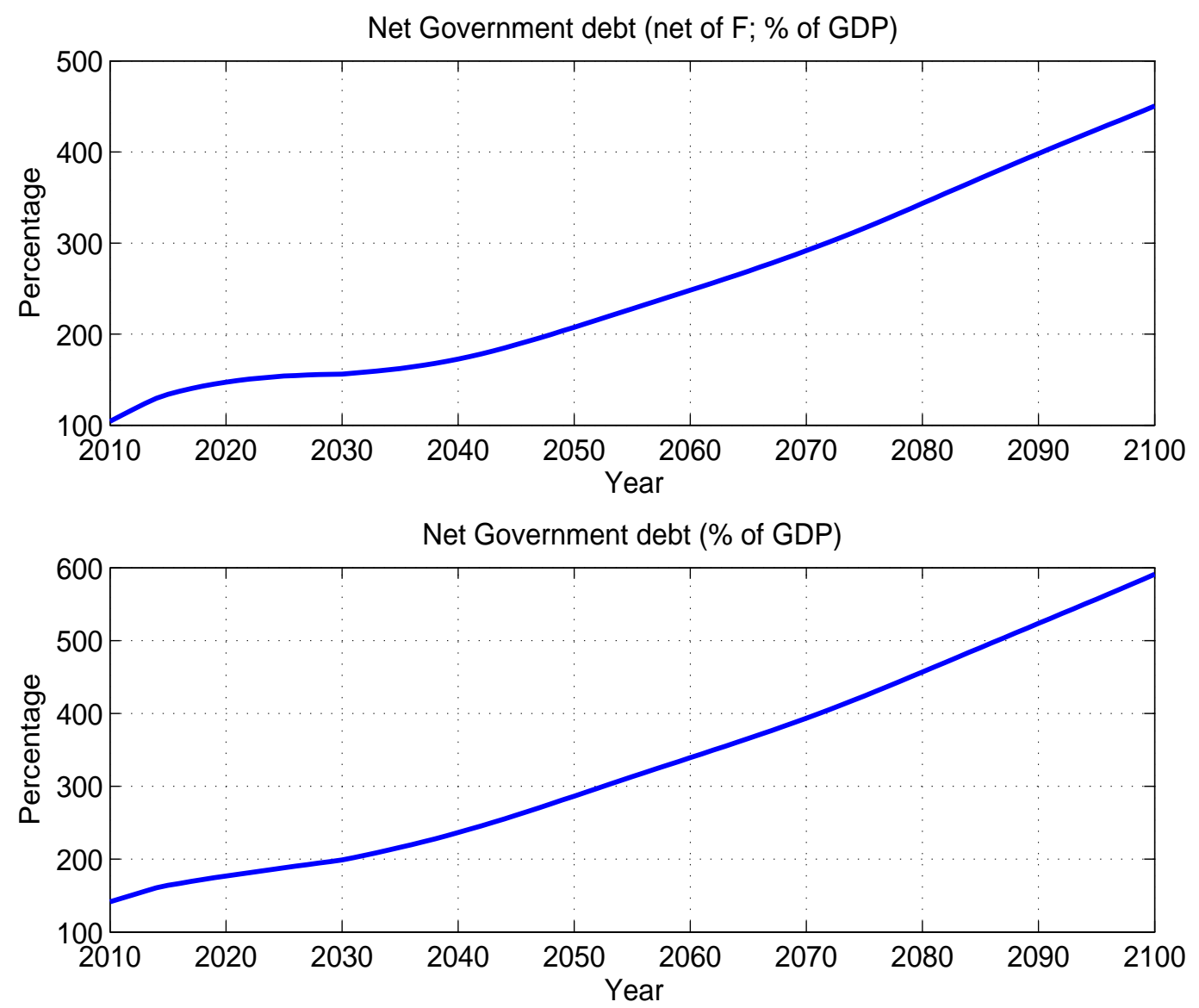

Figure 19: Pension Fund

The second reason for the positive effect of higher FLFP $(\mathrm{C})$ on the fiscal projections is portrayed in Figure 21. 


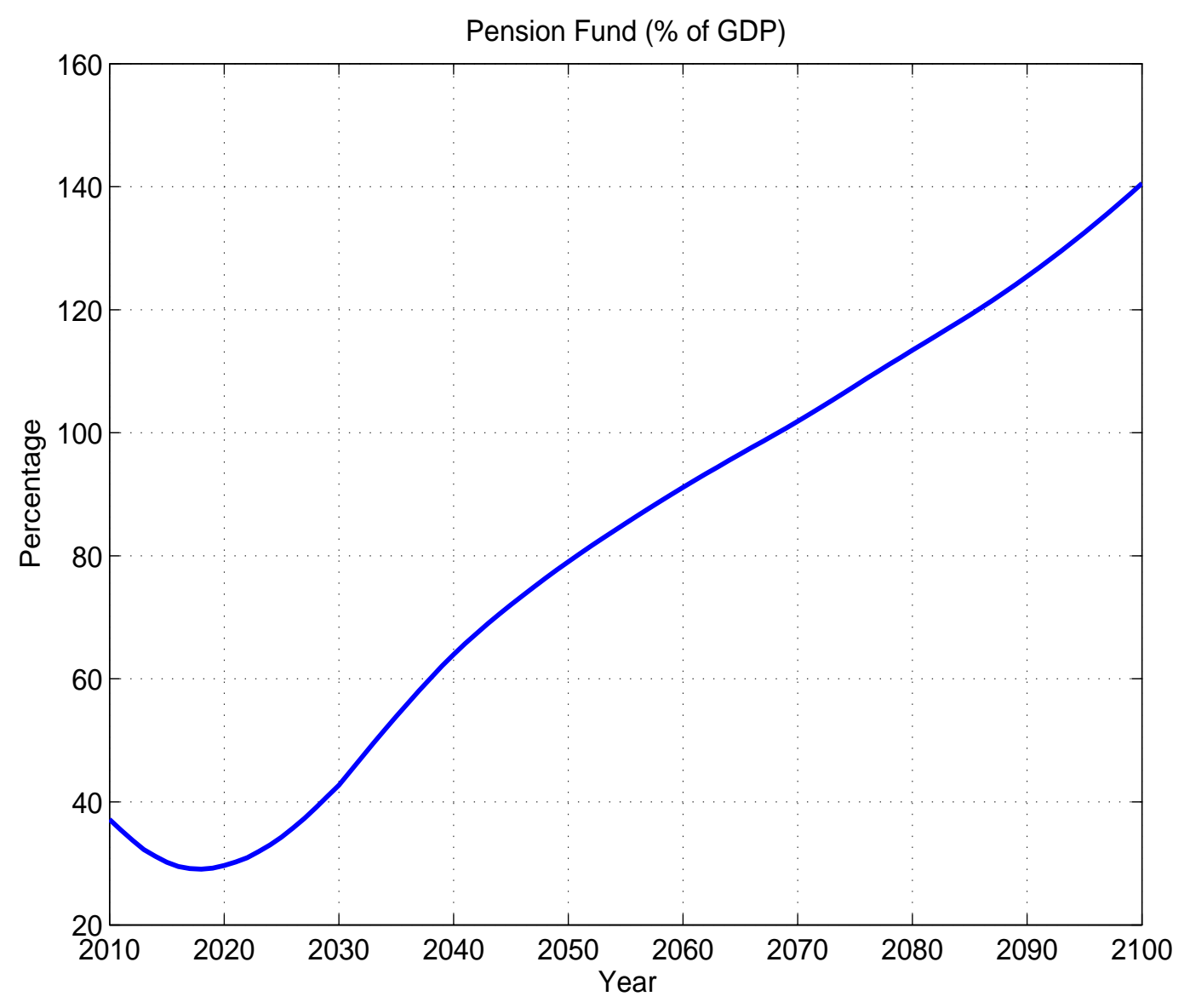

Figure 20: Pension Fund

When females participate in labor market activities at rates and salaries comparable to their male counterparts, the non-pension part of the budget is almost permanently brought to balance. In addition, Figure 21 also demonstrates the significant short term reduction in the pension deficit, with an eventual increase back to about $3 \%$ in the long run. 


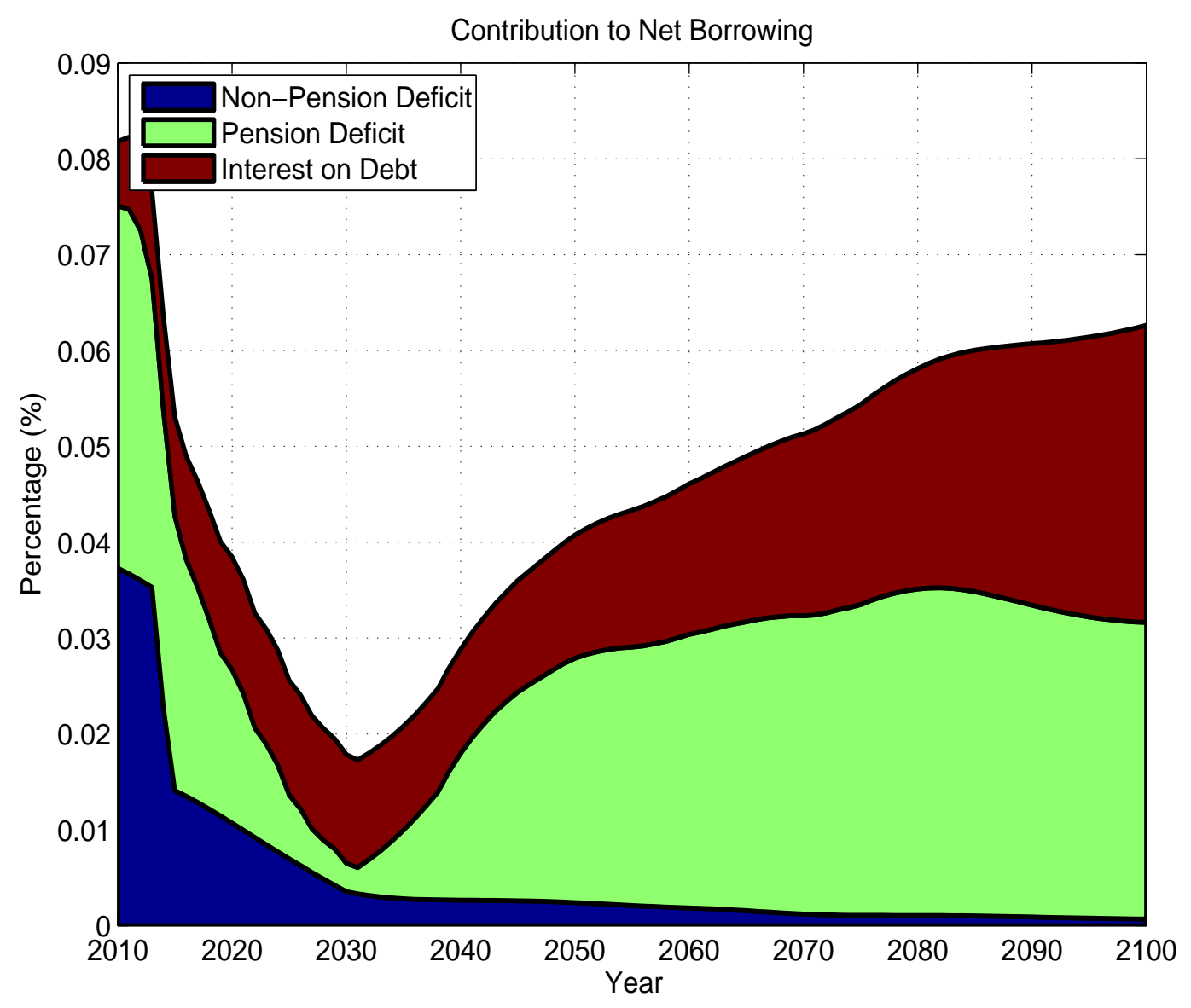

Figure 21: Sources of Net Borrowing Requirements

These results emphasize the quantitative importance of raising the female labor force participation rates in Japan. With positive effects in both the pension and the non-pension (and therefore in the interest burden as well), designing policies that incentivize higher labor market activities among females seem very promising. 


\section{Conclusion}

TBW. 


\section{References}

Aguiar, M. and E. Hurst (2009). Deconstructing lifecycle expenditure. NBER Working Paper Series, No. 13893.

Attanasio, O., S. Kitao, and G. L. Violante (2007). Global demographic trends and social security reform. Journal of Monetary Economics 54(1), 144-198.

Braun, R. A. and D. Joines (2011). The implications of a greying japan for public policy. Working Paper.

Genda, Y. and R. Kambayashi (2002). Declining self-employment in japan. Journal of the Japanese and International Economies 16(1), 73-91.

Gunji, H. and K. Miyazaki (2011). Estimates of average marginal tax rates on factor incomes in Japan. Journal of The Japanese and International Economies 25(2), 81-106.

Hansen, G. and S. İmrohoroğlu (2011). Fiscal reform and government debt in Japan: A neoclassical perspective. Working paper.

Hayashi, F. and E. C. Prescott (2002). The 1990s in Japan: A lost decade. Review of Economic Dyamics 5(1), 206-235.

Hoshi, T. and T. Ito (2012). Defying gravity: How long will japanese government bond prices remain high? NBER Working Paper 18287.

Hoshi, T. and A. Kashyap (2012). Policy options for japan's revival. NIRA Report.

İmrohoroğlu, S. and N. Sudo (2010). Productivity and fiscal policy in Japan: Forecasts from the standard growth model. IMES Discussion Paper Series, 10-E-23.

İmrohoroğlu, S. and N. Sudo (2011). Will a growth miracle reduce debt in japan. IMES Discussion Paper Series, 11-E-01.

Lise, J., N. Sudo, M. Suzuki, K. Yamada, and T. Yamada (2013). Wage, income and consumption inequality in japan, 1981-2008: from boom to lost decades. Working paper. 
Ministry of Health, Labour and Welfare (MHLW), Pension Bureau (2011). Annual report on the public pension system (in japanese, Kosei nenkin hoken, Kokumin nenkin jigyo no gaikyo).

Sakuragawa, M. and K. Hosono (2010). Fiscal sustainability of Japan: A dynamic stochastic general equilibrium approach. Japanese Economic Review 61(4), 517-537. 


\section{A Computation of consumption profile}

As an alternative way of calculating individual consumption profiles, we follow Attanasio, Kitao, and Violante (2007) and assume that individual maximize their lifetime utility subject a lifetime budget constraint. That is, we maintain the complete markets assumption and allow individuals to optimize in this environment.

In particular, assume that individuals maximize

$$
\sum_{i=1}^{I} \beta^{i} S_{i, t+i} \Omega_{i, t+i} \frac{c_{i, j, t+i}^{1-\theta}}{1-\theta}
$$

where $\Omega_{i, t+i}=1+d_{t, i} \nu$, subject to 4 .

Individuals optimization gives

$$
\frac{c_{i+1, j, t+i+1}}{c_{i, j, t+i}}=\left(\beta R_{a, t+i+1} \frac{1+\tau_{c, t+i}}{1+\tau_{c, t+i+1}} \frac{\Omega_{i+1, t+i}}{\Omega_{i, t}}\right)^{1 / \theta} \equiv g_{i+1, t+i}^{c}
$$

where $g_{i+1, t+i}^{c}$ is defined as the growth rate of consumption from age $i$ at time $t+i$ to age $i+1$ at time $t+i+1$.

The discounted present value of total lifetime consumption expenditures of an individual of age 1 of gender $j$ at time $t+1$ is given by

$$
\bar{c}_{1, j, t+1}=c_{1, j, t+1}\left[\left(1+\tau_{c, t+1}\right)+\sum_{i=1}^{I-1}\left(1+\tau_{c, t+i+1}\right) \prod_{k=1}^{i} \frac{s_{k+1, j, t+k}}{R_{a, t+k+1}} g_{k+1, t+k}^{c}\right]
$$

The same object for an individual of age $i^{*}$ and gender $j$ at time $t+i^{*}$ is given by

$$
\bar{c}_{i^{*}, j, t+i^{*}}=c_{i^{*}, j, t+i^{*}}\left[\left(1+\tau_{c, t+i^{*}}\right)+\sum_{i=i^{*}}^{I-1}\left(1+\tau_{c, t+i^{*}+i}\right) \prod_{k=i^{*}}^{i} \frac{s_{k+1, j, t+k}}{R_{a, t+k+1}} g_{k+1, t+k}^{c}\right]
$$

The discounted present value of total lifetime earnings of an individual of age 1 , gender $j$, at time $t+1$ is given by 


$$
\bar{y}_{1, j, t+1}=\tilde{y}_{1, j, e, t+1}+\sum_{i=1}^{I-1} \prod_{k=1}^{i} \frac{s_{k+1, j, t+k}}{R_{a, t+k+1}} \tilde{y}_{k+1, j, t+k+1},
$$

where $\tilde{y}_{i, j, t+i}=\sum_{e} \frac{n_{i, j, e, t+i}}{\sum_{e} n_{i, j, e, t+i}}\left[\left(1-\tau_{l, t+i} y_{i, j, e, t+i}-\tau_{p, t}\left(y_{i, j, e, t+i}\right)-p_{i, j, t+i}+\right.\right.$ $\left.t r_{i, j, e, t+i}\right]$.

Similarly, for an age $i^{*}$ individual of gender $j$ at time $t+i^{*}$ we have

$$
\bar{y}_{i^{*}, j, t+i^{*}}=\tilde{y}_{i^{*}, j, e, t+i^{*}}+\sum_{i=1}^{I-1}\left(\prod_{k=i^{*}}^{i} \frac{s_{k+1, j, t+k}}{R_{a, t+k+1}}\right) \tilde{y}_{i+1, j, t+i}+R_{a, t+i^{*}} a_{i^{*}, t+i^{*}} .
$$

We obtain $a_{i^{*}, t+i^{*}}$ from the budget equation lagged once:

$a_{i^{*}, t+i^{*}}=\left(1 / s_{i^{*}-1, j, t+i^{*}-1}\right)\left[\tilde{y}_{i^{*}-1, j, t+i^{*}-1}+R_{a, t+i^{*}-1} a_{i^{*}-1, t+i^{*}-1}-\left(1+\tau_{c, t+i^{*}-1}\right) c_{i^{*}-1, j, t+i^{*}-1}\right]$.

Individual optimization in this complete markets setting implies $\bar{c}_{i^{*}, j, t+i^{*}}=$ $\bar{y}_{i^{*}, j, t+i^{*}}$ which yields

$$
c_{i^{*}, j, t+i^{*}}=\frac{\bar{y}_{i^{*}, j, t+i^{*}}}{\left(1+\tau_{c, t+i^{*}}\right)+\sum_{i=i^{*}}^{I-1}\left(1+\tau_{c, t+i^{*}+i}\right) \prod_{k=i^{*}}^{i} \frac{s_{k+1, j, t+k}}{R_{a, t+k}} g_{k+1, t+i^{*}}^{c}}
$$

\section{B Estimation of consumption profile}

We use the Family Income and Expenditure Survey (FIES), which is compiled by the Statistics Bureau, Japanese Ministry of Internal Affairs and Communications, for the period 1981-2008 to estimate individual's consumption profile by $_{\text {age. }}{ }^{22}$ The FIES is a monthly diary survey that collects the earnings and expenditures of households and it also reports characteristics including household members' ages, gender, occupation, and marital status. The survey contains approximately 8,000 households per month and has a panel structure although we do not use the panel dimension directly. We define consumption

\footnotetext{
${ }^{22}$ For more details on the dataset, see Lise et al. (2013)
} 
as the sum of nondurable, service, semidurable and durable expenditures, excluding housing expenditure. We equivalize the household consumption using OECD equivalent scale after deflating the variables with CPI.

Following Aguiar and Hurst (2009), we run the following regression:

$$
\ln c_{i, t}=\beta_{0}+\beta_{\text {age }} D_{i, t}^{\text {age }}+\beta_{c} D_{i, t}^{\text {cohort }}+\beta_{t} D^{\text {time }}+\beta_{\text {fam }} \mathbf{X}_{i, t}+\epsilon_{i, t},
$$

where $D_{i, t}^{\text {age }}$ is a vector of age dummies (for ages 20-95), $D_{i, t}^{\text {cohort }}$ is a vector of five-year birth cohort dummies, and $D^{\text {time }}$ is a vector of year dummies. $\mathbf{X}_{i, t}$ represents a vector of household characteristics such as a gender dummy, a marital status dummy, the number of adults, and the number of children. We impose the following two restrictions, $\sum_{t=1981}^{2008} \beta_{t}=0$ and $\sum_{t=1981}^{2008} t \beta_{t}=0$, on the regression coefficients. Because of collineality among age, cohort (birth year) and calender year, it is impossible to estimate the age dummies without the restrictions.

We use the age dummies $D_{i, t}^{\text {age }}$ as adult consumption profile controlled by the cohort and time effects. We restrict the age dummies between 20 and 95 because the household head aged over 95 is very few in the dataset. Since the age dummies are not smooth over life cycle, we smooth out the age dummies using polynomials. We extend the consumption profile to age 110 . 